Chapter 9

\title{
Current Therapies and \\ New Pharmacologic Targets for Metastatic Melanoma
}

\author{
Claudriana Locatelli, \\ Fabíola Branco Filippin-Monteiro and \\ Tânia Beatriz Creczynski-Pasa \\ Additional information is available at the end of the chapter \\ http://dx.doi.org/10.5772/55192
}

\section{Introduction}

Malignant melanoma is a tumor that originates from the melanocytes and manifests mainly on the skin. Melanomas are usually strongly pigmented, however amelanotic forms have been observed. Relative to the tumor mass, melanomas have an early tendency to metastasize; the prognosis is therefore poor. Malignant melanoma is responsible for about $90 \%$ of skin cancer related mortality [1]. Several risk factors for the development of melanoma have been identified. Ethnic origin is particularly important with a disease that mostly affects people of European origin. Epidemiological studies have shown that exposure to the sun, especially in childhood, is a major environmental cause of melanoma, and that up to $65 \%$ of the cases of melanoma are frequently related to sunburn $[2,3]$.

While it is easy for cancer prevention, the incidence of melanoma has increased dramatically over the last four decades and melanoma is now one of the most common forms of cancer, with significant morbidity and high mortality due to its propensity to metastasize. It has a high propensity for haematogenous and lymphatic dissemination to regional and distant sites and is poorly responsive to most systemic therapies. The 5-year survival rate for metastatic melanoma is dismal, ranging from $5 \%$ to $10 \%$ with a median survival of less than eight months with treatment $[4,5]$.

The therapies used in advanced cases, such as chemotherapy, radiotherapy, biochemotherapy and vaccine, seem unable to provide a cure or improved survival of becoming a melanoma tumors most refractory to treatment [6,7]. Although surgery and radiation therapy are very important in the treatment of metastatic disease, systemic treatment remains the basis of 
therapy for the majority of patients, including chemotherapy, immunotherapy, or a combination of approaches such as biochemotherapy [8]. Many compounds have been investigated for antitumor activity in melanoma, but the current treatment options for patients with metastatic disease are limited and non-curative in the majority of cases.

Chemotherapy with cytotoxic agents has been used for the treatment of metastatic melanoma for over three decades. Among the antitumoral agents, efficacy is modest in metastatic melanoma including alkylating agents (dacarbazine, temozolomide, nitrosoureas), analogues of platinum (cisplatin, carboplatin) and microtubular toxins (vincas and taxanes), which have been used alone or in combination [8]. Specifically in relation to cytotoxic chemotherapy, dacarbazine used as a chemotherapeutic agent still represents the single most common option [8]. It was demonstrated that combinations of cytotoxic agents can produce low response rates, although higher than monotherapy with dacarbazine, which are associated with increased toxicity and do not extend significantly the survival of patients [8]. Although of limited therapeutic effect, dacarbazine cannot be dismissed as standard therapy for disseminated melanoma, as in evidence-based analysis no other regimen had greater benefits for the patients' survival [9]. By 2011, only two drugs for metastatic melanoma therapy had been approved by the Food and Drug Administration (FDA), which were dacarbazine and a high dose of interleukin 2 (IL-2). In 2011, the FDA approval of vermurafenib (chemotherapy agent) and ipilimumab (monoclonal antibody) for clinical studies raised optimism for the treatment of metastatic melanoma, since the therapies used until then had had serious limitations, and thus the use of novel strategies for melanoma treatment seemed promising. However, the use of these drugs is limited [10]. The strategies to increase the responsiveness of new therapies are the association with other drugs currently in clinical use, such as dacarbazine, although these therapies are under investigation in vitro and in vivo models.

Other new chemotherapies, including drugs that target biological receptors, are currently in development. Among these are bevacizumab, an endothelial growth factor antibody, and sorafenib, a cellular pathway inhibitor [11]. These agents have shown some efficacy in early clinical trials. The lenalidomide is a thalidomide derivative designed to be more effective and less toxic [12]. In a phase I trial, it was found to be well tolerated by patients with metastatic melanoma and to produce immune activation. Another agent of interest that has shown promising results are the anti Bcl-2 antisense (oblimersen), tested in metastatic melanoma. A combination of Bcl-2 antisense and dacarbazine showed better response than dacarbazine alone, although no significant improvement in overall survival was observed $[13,14]$.

Several clinical trials are being carried out to investigate the antitumor efficacy of new agents as well as diverse immunosuppressive therapeutic strategies, including the use of dendritic cells, high-doses of interferon- $\alpha$ (IFN- $\alpha$ ) and/or IL-2 and anti-cytotoxic T lymphocyte-associated antigen 4 (CTLA-4) antibody, alone or in combination with current therapies for treating locally advanced, metastatic and recurrent melanomas [15].

Significant advancements made in the last few years have provided important information on the molecular signalling pathways and gene products, which are frequently deregulated in melanoma stem/progenitor cells and their progenies during melanoma formation and progression to locally advanced and metastatic disease states. Consequently, the combination 
of different molecular biomarkers or cytotoxic agents targeting distinct gene products altered during melanoma development may constitute more promising therapeutic strategies. Several other signal transduction pathways have been found to be constitutively active or mutated in other subsets of melanoma tumors that are potentially targetable with new agents. Among these, NF-kB is another pathway that melanoma tumors use to achieve survival, proliferation, resistance to apoptosis and metastasis. In fact, it has been demonstrated that up regulation of the NF-kB levels is involved in both the progression of melanoma and an increase of its metastatic potential. Therefore, inhibition of NF-kB activation seems to be a promising target for anti-cancer therapies $[16,17]$.

Recent studies have shown that proteasome inhibitors such as bortezomib represent a new class of anticancer agents by degradation inhibition of cell cycle regulatory proteins, such as cyclin-dependent kinase inhibitors and I-kB protein. The efficacy of bortezomib was recently explored in another 2-stage phase 2 clinical trials in combination with other chemotherapeutic agents, including paclitaxel and carboplatin, in patients with advanced solid tumors. The results from these studies evidenced narrow clinical benefit and significant toxicity, hindrances that limit the use of bortezomib [18].

Another compound known to exert numerous pharmacological properties - mostly antioxidant, anti-inflammatory and antiproliferative - is curcumin, a polyphenol present in in Curcuma longa, a species belonging to the ginger family (Zingiberaceae). With regard to antiproliferative activity, it showed pro-apoptotic activity in a variety of tumors in vitro. To achieve these results, curcumin was used in experiments based on melanoma either in vitro or in vivo models. The importance of curcumin also lies in the fact that this drug seems to reduce the metastatic potential of melanoma, which is the main cause of death [19].

Understanding and overcoming resistance pathways by combining current and future agents, identifying biomarkers to improve therapy and discover new therapeutic targets are promising advances in the treatment of melanoma. In light of this, the purpose of this chapter is to summarize the recent advances in the treatment of metastatic melanoma and to describe the current limitations, as well as to comment on promising future strategies to overcome the limitations.

\section{Single agent chemotherapy}

Melanoma is considered a chemotherapy-resistant tumor, but in fact several chemotherapeutic agents show single-agent activity at the level of $10 \%$ to $15 \%$, similar to the efficacy of the chemotherapeutic armamentarium used against other tumor types. Several combination chemotherapy regimens have been tested, but no survival benefit has been demonstrated. Few of these trials have been compared with standard dacarbazine (DTIC) in an adequately powered randomized trial, and even the most extensive of these trials only aimed to detect unrealistically large improvements in overall survival [20]. For the systemic monotherapy of advanced melanoma, several substances are available whose clinical efficacy is comparable. Palliative monochemotherapy can shrink tumors and thus achieve a reduction in tumor- 
related symptoms. The more active agents are the alkylants (dacarbazine, temozolomide, fotemustine, carmustine, semustine), platinum drugs (cisplatin and carboplatin), vinca alkaloids (vindezine and vinblastine), taxanes (docetaxel and paclitaxel), and tamoxifen [7,21]. Table 1 shows the drugs and dosages for monotherapy to melanoma.

\begin{tabular}{|c|c|c|}
\hline Drugs & Dosage & Overall response \\
\hline Dacarbazine & $250 \mathrm{mg} / \mathrm{m}^{2} /$ day for 5 days every 3-4 weeks & $5.3-25 \%$ \\
\hline Temozolomide & $150-200 \mathrm{mg} / \mathrm{m}^{2} /$ day for 5 days every 4 weeks & $13.5-21 \%$ \\
\hline Carmustine & $75-110 \mathrm{mg} / \mathrm{m}^{2}$ & $13-18 \%$ \\
\hline Semustine & $130 \mathrm{mg} / \mathrm{m}^{2}$ & $16 \%$ \\
\hline Fotemustine & 100 mg/m²/day every 3 weeks & $7.4-25 \%$ \\
\hline Cisplatin & $60-150 \mathrm{mg} / \mathrm{m}^{2}$ & $15 \%$ \\
\hline Carboplatin & $400 \mathrm{mg} / \mathrm{m}^{2}$ every 4 weeks & $19 \%$ \\
\hline Vindezine & $3 \mathrm{mg} / \mathrm{m}^{2}$ every 14 days & $12-26 \%$ \\
\hline Vinblastine & $6-8 \mathrm{mg} / \mathrm{m}^{2}$ every 1 week & $13 \%$ \\
\hline Docetaxel & $100 \mathrm{mg} / \mathrm{m}^{2}$ every 21 days & $14 \%$ \\
\hline Paclitaxel & $125-275 \mathrm{mg} / \mathrm{m}^{2}$ & $15 \%$ \\
\hline Tamoxifen & 20 mg/day & $4-13 \%$ \\
\hline Interferon a & $9 \mathrm{~m}-18 \mathrm{~m} \mathrm{IU} / \mathrm{m}^{2} 3 x /$ week continuous administration & $13-25 \%$ \\
\hline Interleukin-2 & \multicolumn{2}{|c|}{$\begin{array}{l}600000 \mathrm{IU} / \mathrm{Kg} \text { as } 15 \text { minute short infusion i.v. every } 8 \text { hours on days } 1-516-21.6 \% \\
\text { (maximum } 14 \text { individual doses) repeat cycle day } 14\end{array}$} \\
\hline
\end{tabular}

Adapted by Garbe et al. (2008) [21] and Mouawad et al. (2010) [7].

Table 1. Single drugs, dosage and their activity in melanoma.

\subsection{Alkylants agents}

\subsubsection{Triazenes}

The alkylating agent dacarbazine (DTIC, dimethyltriazeno imidazole carboxamide) was first introduced some 30 years ago, and it is considered to be the reference of single agent for the management of advanced melanoma. This compound was initially designed as an antimetabolite because it is an analogue of 5-aminoimidazole-4-carboxamide, an intermediate in purine biosynthesis. However, it presented cytotoxicity that is related to the generation of methyldiazonium, which methylates DNA during its metabolism [22]. Methyldiazonium has a half-life of about $0.4 \mathrm{~s}$ in aqueous solution, sufficient time to allow it to reach its target. In 1975 this carboxamide was approved by the Food and Drug Administration (FDA), and has since been considered the standard of metastatic melanoma care. Single-agent DTIC has remained the standard of care for 3 decades, with response 
rates of $8 \%$ to $20 \%$ and mean duration of response of approximately four to six months. Several studies of dacarbazine in the management of metastatic melanoma were published in the early 1970s [23,24]. The first of these trials demonstrated a $19 \%$ response rate in 110 evaluable patients who received dacarbazine in 3-weekly cycles, most frequently at a dose of $250 \mathrm{mg} / \mathrm{m}^{2}$ daily for five days [25]. A second study showed an overall response rate of $28 \%$ in 115 evaluable patients receiving dacarbazine 2.5 or $4.5 \mathrm{mg} / \mathrm{kg}$ daily for ten days of a thirty-day cycle, and another showed response rates approaching $20 \%$ with dacarbazine $150 \mathrm{mg} / \mathrm{m}^{2}$ daily for five days of a thirty-day cycle in 112 evaluable patients [24]. The typical dacarbazine dose is 850 to $1,000 \mathrm{mg} / \mathrm{m}^{2}$ every three weeks [26].

Among the randomized trials in which dacarbazine was used as a comparator arm, the patients treated with dacarbazine with an overall response rate of $13.4 \%$ and median survivals ranging from about six months to eleven months. Given the low response rate, it is unrealistic to expect dacarbazine to have an effect on median survival [27].

Studies suggest that less than $5 \%$ of patients achieve a complete response to therapies with dacarbazine alone or in combination, and less than $2 \%$ of patients survive five years more. The majority of previous reports suggest that long-term survival is restricted to patients with favourable clinical features, such as nodal, cutaneous or pulmonary metastasis [28].

Although dacarbazine presents a relatively small therapeutic response, it is still considered the standard drug for the treatment of melanoma, whereas the drug combination and the use of other drugs do not show effect as monotherapy.

Another problem with associated dacarbazine is the high toxicity. The major toxic effects associated with dacarbazine are the development of neutropenia, thrombocytopenia, alopecia, nausea or vomiting, fatigue and liver damage [29].

Besides its toxicity, dacarbazine has several drawbacks because of its hydrophilicity, which leads to slow and incomplete oral absorption, and therefore the alternative is intravenous administration. Another disadvantage is its high photosensitivity, with a very short half-life (about $30 \mathrm{~min}$ ), decomposing to 2-azah hypoxanthine via an intermediate diazonium species. For this reason, intravenous infusion bags of dacarbazine must be protected from light. These problems have stimulated the synthesis of dacarbazine analogues, the most important of which is temozolomide [20].

Temozolomide is an oral alkylated compound similar to dacarbazine (the most active single agent in primary melanoma), which has $100 \%$ of oral bioavailability and considerable penetration in Central Nervous System tissue, mainly due to its lipophilic character [30]. Moreover, for its acid-stability the molecule remains in cerebro-spinal fluid, where it reaches $30-40 \%$ of plasmatic concentration [31]. For this reason, differently from dacarbazine, temozolomide is employed in the treatment of primitive [32] and metastatic brain tumors [31]. Although the FDA has not approved it for melanoma, temozolomide is widely used and has response rates similar to dacarbazine in melanoma $[26,33]$.

Despite the absence of approval, temozolomide is also used "off-label" in patients with malignant melanoma after standard treatment. Temozolomide has been proven to have an 
equal efficacy (with a 10-20\% response rate) to that of dacarbazine, the most commonly used chemotherapy agent in metastatic melanoma, in a randomized phase III trial [34,35]. However, TMZ administered in monotherapy did not show significant improvement in the overall response rate or median survival time. Nonetheless, the works of Biswas et al. (2006) [36], Chang et al. (2007) [37], Platta et al. (2007) [38] and Mehta et al. (2010) [39] show the efficacy and modest side effects of single-agent TMZ in patients with recurrent or progressive brain metastases.

In a randomized trial comparing temozolomide given for five days every month with dacarbazine given once every 3 weeks, there was no difference in response rate or survival [26]. Despite this, temozolomide offers two potential advantages over dacarbazine. Temozolomide readily crosses the intact blood-brain barrier, which provides enhanced activity against brain metastases. Unfortunately, the objective response rate of melanoma brain metastases to temozolomide is low [37], although there is some indication that treatment with temozolomide is associated with a lower incidence of disease progression in the brain [38,39]. Another potential advantage of temozolomide is that, as an oral agent, continuous dosing is feasible. An extended-dosing schedule of $75 \mathrm{mg} / \mathrm{m}^{2} /$ day for 42 days followed by 14 days off has been used in several clinical trials. This schedule provides six weeks of continuous drug exposure and delivers $50 \%$ more drug over two months compared with the standard schedule of five days every month. However, a phase II trial using extended-dosing temozolomide showed only a $12.5 \%$ response rate [40], which is not different from what would be expected with standard-dosing of temozolomide or of dacarbazine.

Patients that received oral temozolomide at a starting dosage of $200 \mathrm{mg} / \mathrm{m}^{2} / \mathrm{d}$ for five days every 28 days showed median survival time of about eight months, while patients treated with dacarbazine of about seven months. These results showed that treatment with temozolomide presented significantly longer survival, nevertheless no major difference in drug safety was observed. Temozolomide was well tolerated and produced a noncumulative, transient myelosuppression late in the 28-day cycle. The most common nonhematologic toxicities observed were mild to moderate nausea and vomiting, which were easily managed. Temozolomide therapy improved health-related life quality [26].

The most common hematologic side-effect of temozolomide is myelosuppression (similar to that produced by dacarbazine), particularly neutropenia and thrombocytopenia (dose-limiting toxicity). In contrast, nausea and vomiting are limited (10-15\%), whereas the same side effects are remarkably severe and very frequent (i.e. of the order of $90 \%$ ) in patients treated with dacarbazine. Both drugs can induce headache, fatigue, liver toxicity and constipation [34].

Nevertheless, the development of resistance against the treatment is very common. There are likely multiple mechanisms of chemotherapy resistance specifically for dacarbazine or temozolomide, such as DNA repair of the adduct formation (O6-guanine) with the O6methylguanine-DNA methyltransferase [26,41]. Other mechanisms of resistance include Bcl-2 overexpression, silencing of apoptotic protease activating factor-1 gene (a key mediator of apoptosis), and activation of proliferative and antiapoptotic signalling pathways, including the mitogen-activated protein kinase and phosphoinositide 3-kinase/Akt pathways $[34,35,42-44]$. In addition, NF- $\kappa \mathrm{B}$ activation of its down-stream target genes (angiogen- 
esis, adhesion, antiapoptosis, and chemokine growth factors) likely plays a central role in the proliferation and chemotherapy resistance observed in melanoma [45-47]. It is well established that chemotherapy itself can induce NF- $\kappa B$ activation in cancer cells $[46,47]$. Any number of these or other biological processes are likely important to chemotherapy resistance in melanoma.

In an attempt to reduce resistance to chemotherapy in patients with melanoma, new therapies are introduced including the combination of temozolomide and dacarbazine with other chemotherapeutic drugs that have similar mechanism of action or act in different ways. Alternatives used in polychemotherapy in treating melanoma or as monotherapy are the nitrosoureas such as fotemustine.

\subsubsection{Nitrosoureas}

The nitrosoureas (carmustine, lomustine, semustine and fotemustine) all have single agent activity in melanoma because they cross the blood-brain barrier, thus enabling its use in the treatment of metastatic melanoma. However, at conventional doses, little or no activity was observed against melanoma brain metastases, and overall response rates were low, with only a few complete remissions and short response durations [7,48]. Fotemustine is probably the most active nitrosourea against metastatic melanoma, and especially against cerebral metastasis; its efficacy has been widely demonstrated through several phase II studies.

In patients without brain metastasis treated with fotemustine, the median time for the development of brain metastasis was longer as compared to patients treated with dacarbazine (22.7 months vs. 7.2 months) [49]. It has been widely tested in Europe and has shown overall response of $20-25 \%$, including $5-8 \%$ of complete response rates, and it was the first drug to show significant efficacy in brain metastases [50,51].

A multicenter trial of monotherapy was undertaken in 153 evaluable French patients, in which a response rate of $24.2 \%$ was obtained. In phase II studies fotemustine was administered intravenously as a rapid infusion, at a dose of $100 \mathrm{mg} / \mathrm{m}^{2}$ on days $1,8,15$, then after four to five weeks every three weeks for maintenance. These studies showed response rates between $16 \%$ and $47 \%$ in non-visceral metastasis, and long-term survival without metastasis was reported $[50,52,53]$.

In a phase III clinical trial of fotemustine $\left(100 \mathrm{mg} / \mathrm{m}^{2}\right.$ weekly for three weeks) versus dacarbazine ( $250 \mathrm{mg} / \mathrm{m}^{2} /$ day for five days every four weeks), the response rate for fotemustine was $15.2 \%$ versus $6.8 \%$ for dacarbazine [49].

Previous preclinical studies have indicated that fotemustine inhibits enzymes involved in the ribonucleotide reduction pathway (i.e. DNA synthesis), whereby responding patients appeared to favour the thioredoxin reductase/thioredoxin electron transfer to ribonucleotide reductase, whereas non-responders expressed the alternate glutathione reductase/glutaredoxin mechanism. The $47 \%$ response rate obtained in these studies vs. the $24 \%$ reported previously for fotemustine may reflect variations in enzymes in the ribonucleotide reduction pathway in different patients. However, the efficacy of fotemustine against advanced melanoma warrants 
more extensive trials of this drug, especially because the quality of life of the patients during and after chemotherapy was not severely affected [54].

Fotemustine was well tolerated by the patients, with the only mild side effects being thrombocytopenia, leukocytopenia in $40 \%$ patients, and easily controlled nausea/vomiting [55].

\subsection{Platinum derivatives}

Cisplatin and carboplatin have shown modest activity as single agent therapy in patients with metastatic melanoma. Cisplatin and carboplatin showed good activity against human melanoma cell line, but during in vivo study it did not improve the response comparing with other drugs used in monoterapy of melanoma treatment. It has been shown that cisplatin induced a $15 \%$ response rate with a short median duration of three months [8]. Evidence that the activity of cisplatin may be dose-dependent has come from single institution studies. Cisplatin is also used as a palliative in selected patients with malignant melanoma and central nervous system metastases. It was shown that cisplatin can be administered alone via intracarotid infusion in doses varying from 40 to $75 \mathrm{mg} / \mathrm{m}^{2}$, but the response is not satisfactory, as only about $13 \%$ of the patients presented stabilization of the disease [56]. With regard to carboplatin, in a study on 26 chemotherapy naive metastatic melanoma patients, a response rate of $19 \%$ with five partial responses has been reported, and thrombocytopenia was the dose-limiting toxicity [57]. Oxaliplatin is a platinum analogue, which cytotoxic activity observed in an in vitro assay appears to be significantly superior to that of carboplatin. Its activity becomes comparatively closer to that of cisplatin as exposure time increases. Indeed, at a $24 \mathrm{~h}$ exposure oxaliplatin appears to be significantly more active than cisplatin [58]. Preclinical data have confirmed its non-overlapping spectrum of activity with cisplatin, including acquired and intrinsic platinum resistant cell lines [59]. In a small phase II trial by Evans et al. (1987) [60], no objective response was observed from 10 patients who had previously failed to respond to chemotherapy.

\subsection{Vinca alkaloids}

The vinca alkaloids, especially vindesine and vinblastine, are usually used in melanoma treatment. A phase II study by Mohammed et al. (2000) [61] with vinorelbine $30 \mathrm{mg} / \mathrm{m}^{2} /$ week by intravenous bolus with 21 patients no complete or partial response was observed. The estimated median progression-free survival was two months, and the estimated median overall survival was six months. Patients received vinorelbine at a dose of $30 \mathrm{mg} / \mathrm{m}^{2}$ on days one and eight of a 21-day cycle, on an outpatient basis. Thirteen patients were included in the study, and received 64 cycles. All patients were assessable for response, toxicity and survival. The median progression-free survival was 3.3 months and the estimated median overall survival was 8.1 months. Vinorelbine as a single agent on days one and eight of a 21-day cycle has a favourable toxicity profile, but seems to have no relevant clinical activity in patients with metastatic melanoma [62] Vindesine is frequently included in combination regimens for the treatment of malignant melanoma and head and neck cancer, although its single-agent activity in these diseases is modest (average of 14 and $12 \%$ response rates, respectively) [63]. Similarly, another study that investigated the usefulness of vindesine monotherapy as salvage therapy in stage IV melanoma patients who had previously failed to respond to chemotherapies also 
failed; the treatment with vindesine $3 \mathrm{mg} / \mathrm{m}^{2}$ given to the patients every two weeks in a median of three treatments was stopped due to the disease progression. The median survival after starting vindesine therapy was four months. In this study the authors concluded that vindesine monotherapy is ineffective in stage IV melanoma patients [64]. A phase II study by Retsas et al. (1979) [68] showed a 30\% rate response in 25 patients' treatment with vindesine, but with pronounced side effects. Apart from a low rate response the vinorelbine showed significant toxicity, including febrile neutropenia, granulocytopenia, leukopenia, asthenia, nausea, neuropathy, myalgia, dyspnea and fatigue [61].

\subsection{Taxol}

Preclinical studies indicate that taxanes disturb the cytoskeleton architecture and stabilize microtubules, causing mitotic arrest [65]. Taxol is a major new antitumor agent with significant activity against a number of human cancers. Preclinical investigation demonstrated significant activity against B16 melanoma and against cells derived from melanoma in a human stem cell assay [66]. Studies in phases II and III have shown that taxol has activity against melanoma, but the responses were partial with $16.2 \%$ rate response and median duration of approximately five months [67]. Another study with paclitaxel administered at a dose of $100 \mathrm{mg} / \mathrm{m}^{2}$ intravenously on day one each week for six weeks, the median survival was 209 days [68]. In a phase I trial with paclitaxel administered at 200 to $275 \mathrm{mg} / \mathrm{m}^{2}$ over 24 hours every three weeks, there were four partial responses observed in the 12 patients enrolled [69]. A phase II trial with paclitaxel administered at $250 \mathrm{mg} / \mathrm{m}^{2}$ over 24 hours every three weeks in 25 patients resulted in three partial responses (12\%); an additional four patients had durable objective regression although failing to qualify for partial response [74]. An additional 28 evaluated patients were studied in a second phase II study with paclitaxel administered at $250 \mathrm{mg} / \mathrm{m}^{2}$ over 24 hours. Four patients $(14 \%)$ had objective responses with three complete responses [70]. In another study phase II clinical trial, patients received paclitaxel at $80 \mathrm{mg} / \mathrm{m}^{2}$ over one hour, weekly for three weeks, followed by a one-week rest period; the disease status was assessed every other cycle and the treatment was continued until the patients experienced either disease progression or unacceptable toxicity. All patients were considered to be evaluable for toxicity and all patients were included for response assessment in an intention-to-treat analysis. Patients received paclitaxel for a median of two cycles. None of the 27 patients showed a response to treatment; eight patients had stable disease. The median progression-free survival was 1.8 months and the median survival was 7.6 months [76]. A phase II trial achieved with paclitaxel administered at $90 \mathrm{mg} / \mathrm{m}^{2}$ on days one, five, and nine every three weeks demonstrated a $15.6 \%$ response in $5 / 32$ patients [71].

Docetaxel showed an average response rate of $11.4 \%$ in three phase II clinical trials. In an assay performed by the Enzig group, they administered $100 \mathrm{mg} / \mathrm{m}^{2}$ docetaxel every three weeks to chemotherapy naive patients. Two out of $35(6 \%)$ of the patients responded with one complete response. Both these responses lasted longer than two years [65]. In a phase II clinical trial, 38 patients were also treated with $100 \mathrm{mg} / \mathrm{m}^{2}$ docetaxel every three weeks and evaluated after two cycles; five partial responses were noted in the 30 evaluable patients (17\%) [72]. 
The most common toxicity of taxois is haematological, mainly related with neutropenia. Additional toxicities included hypersensitivity reaction and diarrhoea, peripheral neuropathy, fatigue, fluid retention and oral mucositis [72,73].

\subsection{Tamoxifen}

In 1976, Fischer and collaborators reported the presence of estrogen receptors on human melanoma cells derived from metastatic tumors [74]. Following a preliminary report, studies were performed with tamoxifen in the treatment of melanoma, either as a single agent or more commonly in combination with other chemotherapeutic agents. In a meta-analysis study it was demonstrated that tamoxifen does not improve the overall response rate, complete response rate or survival rate when administered as chemotherapy regimens. The rate responses ranged from zero to $10 \%$ [75]. However, for women 50 years of age or older treated with tamoxifen alone, a response rate of $25 \%$ was observed. Despite these promising results, a subsequent phase II trial published in 1992 showed a response rate of only $4.9 \%$ in postmenopausal women treated with tamoxifen $40 \mathrm{mg}$ daily (14). In phase II studies the patients treated with tamoxifen $100 \mathrm{mg} / \mathrm{m}^{2}$ did not show objective response [76,77]. Another study by Aamdal et al. (1994) [78] reported that the enzyme tyrosinase could mimic estrogen receptors binding, leading to the possibility that this or other interfering substances could account for apparent estrogen receptors activity and the failure to correlate this activity with response to tamoxifen. A remaining controversial question is the inclusion of the antiestrogen in different active chemotherapy regimens, because clinical investigations on the role of tamoxifen in single agent of melanoma have produced inconclusive results.

\subsection{Immunotherapy}

The relationship between melanoma and the immune system has been recognized, spontaneous tumor regression in patients with metastatic melanoma have suggested that immunotherapy might have a greater impact on the outcome of metastatic melanoma than in other cancers [7]. Immune based treatment using biologic response modifiers, especially interleukin-2 and interferon- $\alpha$, which have important roles in both adjuvant therapy and in the treatment of metastatic melanoma, may became an antimelanoma strategy [7,79]. However, the landscape for late-stage treatment options has changed recently, with FDA approval in March 2011 for a new immunotherapy drug ipilimumab for treatment of metastatic melanoma [80]. The Ipilimumab, a humanized monoclonal antibody against CTLA-4, is actually a unique way of enhancing patients' immune response against tumors [81].

\subsubsection{Interferon alpha (IFN- $\alpha)$}

Interferons represent a family of glycoproteins with a broad spectrum of effects including antiviral, immunomodulatory, antiproliferative, prodifferentiating and antiangiogenic $[82,83]$.

Interferon- $\alpha$ (INF- $\alpha$ ) has shown antitumor activity in metastatic malignant melanoma, both as single-agent therapy and in combination with chemotherapeutic agents. As a single agent, IFN- $\alpha$ yields an objective response rate of approximately $15 \%$ of responses with less than $5 \%$ 
of complete response rates and median response duration of between six and nine months with a maximum of 12 months for the best studies [84,85]. Patients that received INF- $\alpha$ intravenously for one month and $10 \mathrm{MIU} / \mathrm{m}^{2}$ subcutaneously three times per week for 48 weeks showed a significantly increased overall survival rate, with a median follow-up of 6.9 years (Kirkwood et al., 1996)

In a controlled trial of two lower doses of IFN- $\alpha$ conducted in patients in observation or in other regimen of treatment, with an intermediate dose of IFN- $\alpha$ (four weeks with $10 \mathrm{MIU} / \mathrm{m}^{2}$ administered five times per week, followed by $10 \mathrm{MIU} / \mathrm{m}^{2}$ three times per week for one year or five $\mathrm{MIU} / \mathrm{m}^{2}$ three times per week for two years) for 13 or 25 months, intermediate dose IFN- $\alpha$ did not significantly improve distant metastasis free interval or overall survival outcomes [28]. Low-dose IFN- $\alpha$ also failed to improve survival outcomes versus observation alone when patients were treated with three $\mathrm{MIU} / \mathrm{m}^{2}$ two times weekly for six months or three $\mathrm{MIU} / \mathrm{m}^{2}$ three times weekly for two or three years [86-88]. Clinical data were recorded by IFN$\alpha$ dose: high $\left(20 \mathrm{MIU} / \mathrm{m}^{2}\right)$, intermediate $\left(5-10 \mathrm{MIU} / \mathrm{m}^{2}\right)$, low $\left(3 \mathrm{MIU} / \mathrm{m}^{2}\right)$, and very low $(1 \mathrm{MIU} /$ $\mathrm{m}^{2}$ ) doses. Groups were also stratified by duration of treatment ( 6 months, $12-18$ months or 24 months). Although there was a statistically significant overall survival benefit for treatment of patients with IFN- $\alpha$, this assimilation did not find evidence of a clear difference in overall survival with different dose levels or duration of the treatments [89]. The mechanism of the therapeutic effects of IFN- $\alpha$ is not completely known. Additional data from Håkansson et al. (1998) [95] and Yurkovetsky et al. (2007) [96] revealed significant decreases of serum levels of immunosuppressive and tumor angiogenic/growth stimulatory factors and increased levels of antiangiogenic. This study also demonstrated a profile of pro-inflammatory cytokines that may help to predict response to therapy. A fundamental question has been raised regarding whether the benefit of IFNs such as immunologic, antiangiogenic, or other antitumor effects would persist long-term or if it would require prolonged, and perhaps indefinite, exposure to IFN- $\alpha$ [90]. When using IFN- $\alpha$ in the long term, the tolerability needs to be weighed up. IFN$\alpha$ induces acute flu like symptoms and widespread haematological and nonhaematological organ toxicity, dose-dependent fatigue/anorexia, and neuropsychiatric side effects that may endanger compliance over the course of several years' therapy [21].

\subsubsection{Interleukin-2 (IL-2)}

IL-2, a natural product secreted by $\mathrm{CD}^{4+} \mathrm{T}$ lymphocytes, was described as a $\mathrm{T}$ cell growth factor, which plays a central role in immune regulation. However, IL-2 can also modulate immunological effects by stimulating HLA-restricted or non-restricted cytotoxic cell, activate natural killer cells, B lymphocytes, macrophages and induce lymphokine-actived killer cells in vitro as well as the production of other cytokines [7]. The FDA initially approved IL-2 for the treatment of patients with metastatic melanoma in 1998. High-doses of IL-2 (600.000-720.000 $\mathrm{IU} / \mathrm{Kg}$ every eight hours on days 1-5 and 15-19) produce overall response rates in $15-20 \%$ of patients with complete responses in 4-6\% [91-93]. In phase II trials in patients with metastatic melanoma, a high-dose regimen of $600.000 \mathrm{U} / \mathrm{Kg}$ IL-2 was administered every eight hours for up to 14 doses; only $16 \%$ presented objective response and a small percentage of patients (5\%) experienced long-term, durable complete response, which has been interpreted as a potential 
cure [84]. However, this therapy has not been shown to improve overall survival in the patient population and has never been evaluated in a phase III setting [94,95]. In addition, IL-2 treatment-related toxicity is severe, which include hemodynamic toxicity (e.g. hypotension, edema, weight gain and decreased renal function), respiratory insufficiency, and neurotoxicity $[96,97]$. Based on the available data assessing prognostic factors and patient selection, patients with non-visceral metastases and fewer metastatic sites have a much higher response rate. In these select patients, high dose IL-2 may be considered for first-line therapy [98].

\subsubsection{Ipilimumab a new hope for metastatic melanoma}

Stimulation of tumor-expressed Cytotoxic T-Lymphocyte Antigen 4 (CTLA-4) with soluble ligands or agonistic mAb triggers the apoptosis $[99,100]$, as well as inhibition of proliferation and secretion of angiogenic cytokines [101]. Preclinical studies showed that blocking CTLA-4 results in anti-tumor activity and tumor regression in many mice tumor models (prostate, breast, lymphoma, melanoma) [102,103]. Two anti-CTLA-4 monoclonal antibodies, generated by different companies, were tested in clinical trials in metastatic melanoma patients: tremelimumab (Pfizer) and ipilimumab/Yervoy (Bristol Myers Squibb), but only the latter was successful in phase III studies. Based on its ability to prolong survival of previously treated as well as untreated metastatic melanoma patients [104,105], ipilimumab received European Union (2010) [106] and FDA (March 2011) approval.

Widely touted as a therapeutic breakthrough, ipilimumab works by enhancing T-cell activity by modifying the function of the CTLA-4 inhibitory receptor. Ipilimumab is directed against the CTLA- 4 antigen present on the surface of cytotoxic T-lymphocytes. The presence of the CTLA-4 antigen negatively regulates the activity of T-lymphocytes, ultimately suppressing the immune response [107]. Evidence for ipilimumab offers hope for patients with a clearly lethal disease, but also highlights some of the dangers and relative infancy of immunotherapies in the clinical setting [108].

Blocking the CTLA-4 antigen with ipilimumab will stimulate the patient's own immune response, which will be helpful in destroying cancerous cells [109]. Ipilimumab has been studied in more than 2,000 patients with metastatic melanoma and response patterns showing shrinkage of baseline lesions, a decline of tumor burden with a complete response in few patients. An objective response rate of above $30 \%$ was observed in later stages of clinical trials, after failing in the initial stages of the treatment, in which the response rate was $10 \%$. The results of the advanced phase III trials indicate that one third of the patients taking Ipilimumab will receive long-term survival benefits [104]. Objective response rates combining complete response and partial response were in the range of 5-20\% [104,110]. Disease control rates were reported averaging 15-30\%. In contrast, the two therapies approved by the FDA, high-dose of IL- 2 and dacarbazine, are both associated with response rates of only 10 to $20 \%$ and a small percentage of complete response. They are not thought to improve overall survival [104]. Two exciting phase III studies tested the clinical effects of Ipilimumab in advanced metastatic melanoma patients. In the first, 676 participants from 125 different medical centers, who had already been given standard treatments, received Ipilimumab or gp100 vaccine separately, or a combination of both, in a randomized, double-blind manner. Treatment with Ipilimumab 
improved median overall survival rates (10.0 and 10.1 months in the Ipilimumab-treated groups as compared with 6.4 months in the gp100-only treated group). In the second trial [105], 502 patients who had not previously been treated received either dacarbazine (DTIC, standard care chemotherapy) or Ipilimumab in combination with dacarbazine in a double-blind, placebo-controlled manner. In this experiment, Ipilimumab increased overall survival rates from 9.1 to 11.2 months and 3-year survival from $12.2 \%$ to $20.8 \%$. A study of single agent Ipilimumab with intra-patient dose escalation every 2 cycles of therapy also resulted in an increased toxicity with no improvement in the response rates [111]. In this study, patients were initially dosed at $3 \mathrm{mg} / \mathrm{kg}$ every three weeks for two doses. If there was no objective response or higher autoimmune toxicity, the dose was increased to $5 \mathrm{mg} / \mathrm{kg}$ for two doses and then to $9 \mathrm{mg} / \mathrm{kg}$ for two doses. Five out of 46 patients (11\%) achieved an objective clinical response at the expense of $35 \%$ of patients experiencing significant toxicities. The authors concluded that increasing doses of Ipilimumab to increase autoimmune toxicities did not seem to increase the antitumor activity [111]. Adverse effects, mainly immune related in the skin and gastrointestinal track, were experienced by nearly all patients in the two trials, with about half of the patients suffering from severe adverse effects in the second trial and several severe immune effects-related deaths in the first trial. Therefore, these exciting results also demonstrate the complicity of specifically manipulating immune responses.

\section{Multi-drugs combinations}

The disappointing results with single agent chemotherapy led to the evaluation of multi-drug combinations regimens in the 1980s in an effort to improve outcome and enhance response rates in patients with metastatic disease. The combinations of different chemotherapeutic drugs)or cytotoxic agents with cytokines occasionally yield substantially higher remission rates without prolonging overall survival $[7,21]$. The therapeutic schemes that have become established for melanoma are listed in Table 2. The toxicity of combined chemotherapeutics regimes is significantly higher than with monotherapy. Multi-drug combinations can, however, be of palliative use in individual cases and can provide effective treatment for tumor related symptoms. Since regimes are potentially toxic, intensive supportive treatment is crucial for the patient's quality of life [7].

Many of the combination regimens tested in melanoma (see Table 2) have combined dacarbazine with immunologic agents (e.g., IFN, IL-2), hormones (e.g., tamoxifen) or novel biologic agents, each of which individually has shown little single-agent activity. Some of the common combinations of cytotoxic chemotherapeutic regimens used in melanoma are discussed and the few phase III randomized trials that have been published are highlighted.

Historically, promising combination regimens like BOLD (bleomycin, vincristine, lomustine and DTIC) and CVD (cisplatin, vinblastine and DTIC) have induced responses on metastatic lesions in the liver, bone and brain, commonly unresponsive to DTIC alone, even though they have failed to have an impact on patient survival. Several other studies have suggested a significant enhancement of antitumor effect associated with the addition of tamoxifen to 
various cytotoxic regimens [112]. The other drug combinations have been observed and some authors recommend the combination of cisplatin, carmustine, dacarbazine and tamoxifen as reference therapy, even though recently presented results of a randomized phase III trial of this combination versus dacarbazine alone show no statistical difference in survival between the two groups. While a survival benefit from dacarbazine based chemotherapy or dacarbazine alone has never been shown in metastatic melanoma patients and, therefore, the survival has remained unchanged over the past 30 years, some long term survivors have been reported after receiving the "Dartmouth regimen" (Dacarbazine /Carmustine /Cisplatin /Tamoxifen) and/or high doses of IL-2 based regimens, whose role is going to be defined in prospective randomized phase III trials [112].

\begin{tabular}{|c|c|c|}
\hline Scheme & Drugs/dosage & Overall response \\
\hline BHD scheme & $\begin{array}{c}\text { BCNU } 150 \mathrm{mg} / \mathrm{m}^{2} \text { i.v. day } 1 \text {, only every } 2^{\text {nd }} \text { cycle/Hydroxyurea } \\
1500 \mathrm{mg} / \mathrm{m}^{2} \text { oral days } 1-5 / \text { Dacarbazine } 150 \mathrm{mg} / \mathrm{m}^{2} \text { i.v. days } \\
1-5 \text { every } 4 \text { weeks }\end{array}$ & $12.7-30.4 \%$ \\
\hline BOLD scheme & $\begin{array}{c}\text { Belomycin } 15 \text { mg i.v. days } 1+4 / \text { Vincristine } 1 \mathrm{mg} / \mathrm{m}^{2} \text { i.v days } \\
\text { 1+ 5/CCNU } 80 \mathrm{mg} / \mathrm{m}^{2} \text { p.o day } 1 / \text { Dacarbazine } 200 \mathrm{mg} / \mathrm{m}^{2} \text { i.v. } \\
\text { days } 1-5 \text { every } 4-6 \text { weeks }\end{array}$ & $22-40 \%$ \\
\hline DVP scheme & $\begin{array}{l}\text { Dacarbazine } 250 \mathrm{mg} / \mathrm{m}^{2} \text { i.v. days } 1-5 / \text { Vindesine } 3 \mathrm{mg} / \mathrm{m}^{2} \text { i.v } \\
\text { day } 1 / \text { Cisplatin } 100 \mathrm{mg} / \mathrm{m}^{2} \text { i.v day } 1 \text { every } 3-4 \text { weeks }\end{array}$ & $31.4-45 \%$ \\
\hline DVP scheme & $\begin{array}{l}\text { Dacarbazine } 450 \mathrm{mg} / \mathrm{m}^{2} \text { i.v. days } 1+8 / \text { Vindesine } 3 \mathrm{mg} / \mathrm{m}^{2} \mathrm{i} . \mathrm{v} \\
\text { day } 1+8 / \text { Cisplatin } 50 \mathrm{mg} / \mathrm{m}^{2} \text { i.v day } 1+8 \text { every } 3-4 \text { weeks }\end{array}$ & $24 \%$ \\
\hline $\begin{array}{l}\text { CarboTax } \\
\text { scheme }\end{array}$ & $\begin{array}{l}\text { Carboplatin AUC6 i.v day 1, after } 4 \text { cycles reduce dose to } \\
\text { AUC5/Paclitaxel } 225 \mathrm{mg} / \mathrm{m}^{2} \text { i.v. day } 1 \text { every } 3 \text { weeks }\end{array}$ & $12.1 \%$ (second-line) \\
\hline \multirow[t]{6}{*}{ GemTreo scheme } & $\begin{array}{c}\text { Gemcitabine } 1000 \mathrm{mg} / \mathrm{m}^{2} \text { i.v. days } 1+8 / \text { Treosulfan } 3500 \\
\mathrm{mg} / \mathrm{m}^{2} \text { i.v. days } 1+8 \text { every } 4 \text { weeks }\end{array}$ & $\begin{array}{l}\text { 33.3\% (partial remission and } \\
\text { stable disease) }\end{array}$ \\
\hline & $\begin{array}{c}\text { Carmustine } 150 \mathrm{mg} / \mathrm{m}^{2} \text { i.v. }+ \text { Vincristine } 2 \mathrm{mg} / \mathrm{m}^{2} \text { i.v. on day } 1 \\
\text { only }\end{array}$ & $25 \%$ \\
\hline & $\begin{array}{c}\text { Cisplatin } 20 \mathrm{mg} / \mathrm{m}^{2} / \text { day for } 4 \text { days starting on day } 2+ \\
\text { Vinblastine } 1.6 \mathrm{mg} / \mathrm{m}^{2} / \text { day } \times 5 \text { days }+ \text { Dacarbazine } 800 \\
\mathrm{mg} / \mathrm{m}^{2} \text { i.v. on day } 1\end{array}$ & $24 \%$ \\
\hline & $\begin{array}{l}\text { Tamoxifen } 10 \mathrm{mg} \text { twice daily by mouth } 1 \text { week before } \\
\text { chemotherapy + Carmustine } 150 \mathrm{mg} / \mathrm{m} 2 \text { on day } 1+ \\
\text { Dacarbazine } 220 \mathrm{mg} / \mathrm{m}^{2} \text { i.v. + Cisplatin } 25 \mathrm{mg} / \mathrm{m}^{2} / \text { days } 1-3\end{array}$ & $18.5 \%$ \\
\hline & $\begin{array}{l}\text { Dacarbazine } 250 \mathrm{mg} / \mathrm{m}^{2} \text { i.v days } 1-4 \text { every } 3 \text { weeks + } \\
\text { Detorubicin } 120 \mathrm{mg} / \mathrm{m}^{2} \text { i.v. every } 3 \text { weeks }\end{array}$ & $36 \%$ \\
\hline & $\begin{array}{c}\text { Carmustine } 150 \mathrm{mg} / \mathrm{m}^{2} \text { i.v. on day } 1+\text { Cisplatin } 25 \mathrm{mg} / \\
\mathrm{m}^{2} \mathrm{i} . \mathrm{v} . / \text { day on days } 1-3+\text { Dacarbazine } 220 \mathrm{mg} / \mathrm{m}^{2} \mathrm{i} . \mathrm{v} . / \text { day on } \\
\text { days } 1-3+\text { Tamoxifen } 160 \mathrm{mg} \text { orally/day x } 7 \text { days prior to } \\
\text { chemotherapy. Treatment cycles repeated every } 28 \text { days, } \\
\text { BCNU every } 2 \text { cycles }\end{array}$ & $26 \%$ \\
\hline
\end{tabular}




\begin{tabular}{|c|c|c|}
\hline \multirow[t]{4}{*}{ Scheme } & Drugs/dosage & Overall response \\
\hline & Dacarbazine $2.5 \mathrm{mg} / \mathrm{m}^{2}$ i.v. by means of bolus injection on & \multirow{3}{*}{$27 \%$} \\
\hline & days $1-4$ every 4 weeks + Corynebacterium parvum $7 \mathrm{mg}$ i.m. 1 & \\
\hline & week before starting DTIC and at 4-week intervals thereafter & \\
\hline & Dacarbazine $250 \mathrm{mg} / \mathrm{m}^{2}$ i.v. $\times 5$ days, every 3-weeks + & \multirow{2}{*}{$28 \%$} \\
\hline & Tamoxifen $20 \mathrm{mg} / \mathrm{m}^{2}$ orally daily & \\
\hline & CCNU 200 mg/m² once every 6 weeks/Dacarbazine 150 & \multirow{2}{*}{$15 \%$} \\
\hline & $\mathrm{mg} / \mathrm{m}^{2}$ i.v. $\times 5$ days $/ 3$ weeks + CCNU $130 \mathrm{mg} / \mathrm{m}^{2} 1 / 6$ weeks & \\
\hline & Dacarbazine $250 \mathrm{mg} / \mathrm{m}^{2} \mathrm{i} . v . /$ day on days 1-5 + Epirubicin 90 & \multirow{2}{*}{$21 \%$} \\
\hline & $\mathrm{mg} / \mathrm{m}^{2}$ on day 1 every 3 weeks & \\
\hline & Vinblastine $6 \mathrm{mg} / \mathrm{m}^{2} /$ day i.v. on days $1-2+24-\mathrm{h}$ infusion of & \multirow{5}{*}{$10 \%$} \\
\hline & Bleomycin 15 units $/ \mathrm{m}^{2}$ from days $1-5+$ Cisplatin $50 \mathrm{mg} / \mathrm{m}^{2} 1$ & \\
\hline & h i.v. infusion on day 5. After four courses, vinblastine and & \\
\hline & Cisplatin were given alone. Courses repeated on a cycle of 4 & \\
\hline & weeks & \\
\hline & Dacarbazine $100 \mathrm{mg} / \mathrm{m}^{2} 8 \mathrm{~h} \times 6$ days every month/ & \multirow{2}{*}{$24-29 \%$} \\
\hline & Carmustine $150 \mathrm{mg} / \mathrm{m}^{2}+$ Vincristine $2 \mathrm{mg} / \mathrm{m}^{2}$ every 30 days & \\
\hline & Dacarbazine $250 \mathrm{mg} / \mathrm{m}^{2} /$ day i.v. $\times 5$ days every 4 weeks + & \multirow{2}{*}{$25 \%$} \\
\hline & Vindesine 3 mg $/ \mathrm{m}^{2} /$ week & \\
\hline & Dacarbazine $220 \mathrm{mg} / \mathrm{m}^{2}$ on day $1-3+$ Carboplatine AUC 5 & \multirow{2}{*}{$21.3 \%$} \\
\hline & day 1,21 Days & \\
\hline & IFN-a $15 \mathrm{MU} / \mathrm{m}^{2} /$ day i.v. days $1-5 \times 3$ weeks, then $10 \mathrm{MU} / \mathrm{m}^{2}$ & \multirow{3}{*}{$21 \%$} \\
\hline & s.c. $3 x /$ week + Dacarbazine 200 mg/m² daily i.v. days $1-5$ & \\
\hline & starting on day 22 , every 28 days & \\
\hline & Tamoxifen 20 mg/day v.o. starting day 1 + Dacarbazine 200 & \multirow{2}{*}{$18 \%$} \\
\hline & $\mathrm{mg} / \mathrm{m}^{2} /$ day i.v. days $1-5$ every 28 days & \\
\hline & IFN- $\gamma 15 \mathrm{MU} / \mathrm{m}^{2} /$ day i.v. days $1-5 \times 3$ weeks, then $10 \mathrm{MU} / \mathrm{m}^{2}$ & \multirow{3}{*}{$19 \%$} \\
\hline & s.c. $3 x /$ week + orally Tamoxifen 20 mg/day starting day $1+$ & \\
\hline & Dacarbazine 200 mg/m²/day i.v. days $1-5 / 28$ days & \\
\hline & Dacarbazine 800 mg/m² i.v. days 1 and 21 + daily INF-a i.m. 3 & \multirow{3}{*}{$28 \%$} \\
\hline & MIU at days 1-3, 6 MIU days 4-6, and 9 MIU daily thereafter. & \\
\hline & Started concomitantly & \\
\hline & Dacarbazine $800 \mathrm{mg} / \mathrm{m}^{2}$ i.v. days 1 and $21+$ INF-a i.m. 3 MIU 3 & \multirow{2}{*}{$23 \%$} \\
\hline & x/week. Started concomitantly & \\
\hline & Dacarbazine i.v. escalating dose 200 mg/m², 400 mg/m², 800 & \multirow{3}{*}{$21 \%$} \\
\hline & $\mathrm{mg} / \mathrm{m}^{2} / 3$ weeks; IFN-a s.c. starting at $3 \mathrm{MU} /$ day on days $1-3$, & \\
\hline & $9 \mathrm{MU} /$ day on days 4-70, then $9 \mathrm{MU} 3$ x / week & \\
\hline \multicolumn{3}{|c|}{ BCNU = 1,3-bis(chroethyl)-1-nitrosourea (Carmustine) CCNU = Lomustine } \\
\hline 0 d o th th 5 & t al. (2008) [21] and Mouawad et al. (2010) [7]. & \\
\hline
\end{tabular}

Table 2. Multi-drug combinations and their activity in melanoma. 
The Dartmouth Regimen was described for the first time in 1984 with the treatment of 20 patients with melanoma. This association showed promising results, with high response rates of $40 \%$ to $50 \%$ [113,114]. However, another study shows a response rate of $18.5 \%$ with this combination [115]. In another randomized phase II trial, Dartmouth Regimen was compared with dacarbazine alone in patients with melanoma, wherein 60 patients were randomly assigned to receive carmustine $150 \mathrm{mg} / \mathrm{m}^{2}$ intravenously on day one, cisplatin $25 \mathrm{mg} / \mathrm{m}^{2}$ intravenously daily on days one to three, dacarbazine $220 \mathrm{mg} / \mathrm{m}^{2}$ intravenously daily on days one to three, and tamoxifen $160 \mathrm{mg}$ orally daily for seven days. The overall response was $26 \%$, complete responses were $2.5 \%$, with median progression-free survival and the median survival four and nine months respectively. These results show that the combination had limited impact on overall survival when compared with dacarbazine alone, with the additional drawback of high toxicity [116].

In a multicenter phase III trial, 240 patients with measurable stage IV melanoma were randomly selected to receive the Dartmouth regimen (dacarbazine $220 \mathrm{mg} / \mathrm{m}^{2}$ and cisplatin 25 $\mathrm{mg} / \mathrm{m}^{2}$ on days one to three, carmustine $150 \mathrm{mg} / \mathrm{m}^{2}$ on day one every other cycle and tamoxifen $10 \mathrm{mg}$ orally bid). The treatment was repeated every three weeks. The results showed median survival time from randomization of seven months; response rate was $18.5 \%$ when compared with dacarbazine alone this treatment was not better [115]. In addition to the low activity, the Dartmounth Regimen showed high toxicity, mainly bone marrow suppression, nausea, vomiting and fatigue. Although advanced melanoma is often not curable with systemic therapy, the considered use of currently available regimens can induce clinically significant remissions and, possibly, prolong the life of some patients.

Su et al. (2011) [124] evaluated the combination of carmustine $\left(150 \mathrm{mg} / \mathrm{m}^{2}\right.$, on day one every eight weeks), cisplatin ( $25 \mathrm{mg} / \mathrm{m}^{2}$, days one to three every four weeks), dacarbazine (220 $\mathrm{mg} / \mathrm{m}^{2}$ days one to three every four weeks), tamoxifen (10 mg twice a day) and IL-2 18 Million International Units in divided doses by subcutaneous injection three times a week for four weeks. The treatment was repeated for a total of six cycles or until disease progression or unbearable toxicity. The response rate was $32.5 \%$ including $5 \%$ with a complete response, $27.5 \%$ with a partial response and $17.5 \%$ with a stable disease. The median progression-free survival was 6.2 months and median overall survival was 11.3 months. The toxicity associated with IL-2 included indurate injection site, fever, chills, itchy skin, bone pain and myalgia and eosinophilia.

The Dartmouth Regimen was associated with IL-2 and IFN- $\alpha$. In those patients who received sequential immunotherapy, each cycle of chemotherapy was followed by outpatient s.c. IL-2 $\left(10 \times 10^{6} \mathrm{IU} / \mathrm{m}^{2}\right.$, on days three to five, week four; $5 \times 10^{6} \mathrm{IU} / \mathrm{m}^{2}$, on days one, three and five, week five) and s.c. IFN- $\alpha\left(5 \times 10^{6} \mathrm{IU} / \mathrm{m}^{2}\right.$, on day one, week four; on days one, three and five, week five). The overall response rate of patients treated with the combination of chemotherapy and IL-2/IFN- $\alpha$ was $34.3 \%$ with complete responses (10.9\%) and partial responses $(23.4 \%)$. In patients treated with chemotherapy only, the overall response rate was $29.9 \%$ with complete responses $(13.3 \%)$ and partial responses $(16.6 \%)$. There was no significant difference in median progression-free survival (zero months vs. four months) and in median overall survival (12 
months vs. 13 months) for combined chemoimmunotherapy and for chemotherapy, respectively [117].

A prospective randomized phase III clinical trial was performed to assess whether the addition of tamoxifen to the Dartmounth Regimen would ameliorate the responses. The median survival observed was 6.9 months, but the progression-free survival as well as the overall survival was not different from the treatment with Dartmounth Regimen alone [118].

Other chemotherapeutic agents have also been combined with tamoxifen for the treatment of metastatic melanoma. Bajetta et al. (1993) [119] treated two groups of patients sequentially; the first group received carboplatin and cytarabine alone and for the second group, tamoxifen $40 \mathrm{mg}$ was added daily throughout the cycle. Of 21 evaluable patients in the first group, $19 \%$ responded. In contrast, $8 \%$ of patients responded in the tamoxifentreated group. All patients had received prior chemotherapy and/or immunotherapy. In an attempt to confirm synergism between tamoxifen and cisplatin and to overcome clinically established cisplatin resistance, McClay et al. (1995) [120] treated 24 metastatic melanoma patients with cisplatin $100 \mathrm{mg} / \mathrm{m}^{2}$ every three weeks; $13 \%$ of patients responded. Those who failed to respond clinically (cisplatin resistant) were then treated with the same dose of cisplatin plus tamoxifen $160 \mathrm{mg}$ on day one, followed by $20 \mathrm{mg}$ daily throughout the three-week cycle. In 19 assessable patients, 16\% achieved a complete response or partial response as conventionally defined; however, when the authors included mixed responses, the overall response rate (32\%) was statistically significantly. In a phase I study, McClay et al. (1995) [120] treated successive groups of patients with escalating doses of tamoxifen and weekly cisplatin $80 \mathrm{mg} / \mathrm{m}^{2}$. Patients received up to $320 \mathrm{mg} / \mathrm{m}^{2}$ at the time of the report and none of the patients responded at doses less than $240 \mathrm{mg} / \mathrm{m}^{2}$.

Studies have combined chemotherapy, immunomodulators and tamoxifen. Antoine et al. (1995) [121] added tamoxifen to a regimen of cisplatin, IL-2, and IFN- $\gamma$. The response rate with tamoxifen (41\%) was lower than the response rate observed without tamoxifen (54\%). Rixe et al. (1994) [122] treated 91 patients with high-dose cisplatin, IL-2, IFN- $\alpha$ and tamoxifen. The trial was stopped prematurely due to an increased frequency of sepsis and because the response rates were similar to those observed in historical controls that did not receive tamoxifen.

Fierro et al. (1993) [123] treated 32 patients with a combination including carmustine, cisplatin, dacarbazine and tamoxifen, which showed an overall response rate of $47 \%$, complete response of $16 \%$, partial response of $31 \%$ and median survival of 10 months. The pretreatment with INF$\alpha$ did not modify the survival or the response rate.

In a phase II trial with a high dose of tamoxifen and cisplatin administered weekly were used; tamoxifen was started on day one with a dose of $240 \mathrm{mg} /$ day. Cisplatin $\left(80 \mathrm{mg} / \mathrm{m}^{2}\right)$ was started on day two and repeated weekly for a total of three weeks. During week four, the patient was not treated with cisplatin but was evaluated for response. If disease stabilization or regression was documented, the patient received a second three-week cycle of cisplatin and was then reevaluated for response. Patients with progressive disease at any evaluation were removed from the study. In 28 consecutive patients, the overall response rate was $32 \%$. Toxicity was 
primarily nausea and vomiting. While this combination presented activity, the overall response rate was not significantly better that that observed with the original Dartmouth regimen and besides, the toxicity is substantial [128].

The cisplatin, vinblastine and bleomycin were combined in the treatment of 51 patients with metastatic melanoma; among these patients only $22 \%$ had complete or partial response. However, the response durations were brief and the toxicity was substantial. The authors concluded that such a combination was not sufficiently beneficial to warrant its use in metastatic melanoma [132] Bajetta et al. (1982) [133] treated 22 patients with metastatic melanoma with vinblastine, bleomycin and cisplatin. In this study, the survival rate was 10 months and the results showed that this combination did not exceed the treatment with dacarbazine. Nathanson et al. (1981) [134] also studied this combination and the patients showed a median duration of response of 26 weeks associated with significant toxicity, marrow suppressive, gastrointestinal, pulmonary and mucocutaneous.

The BOLD scheme (bleomycin, vincristine, lomustine plus dacarbazine) included bleomycin at 7.5 units subcutaneously in the first course and 15 units in subsequent courses on days one and four; vincristine at $1 \mathrm{mg} / \mathrm{m}^{2}$ intravenously on days one and five; lomustine at $80 \mathrm{mg} / \mathrm{m}^{2}$ on day one and dacarbazine $200 \mathrm{mg} / \mathrm{m}^{2}$ intravenously on days one through five. These treatments showed $9 \%$ complete response, $31 \%$ partial response and $17 \%$ stabilization of disease and overall median survival of 31 weeks. The authors concluded that the BOLD scheme was an effective alternative treatment for metastatic melanoma, because the overall toxicity was moderate [135]. Several other works that used the BOLD scheme in combination with IFN- $\alpha$ showed better results with response rates from 13 to $24 \%$, which is not significant when compared with the treatment with the BOLD scheme alone, but patients with soft tissue or lung metastases may achieve more complete response [124]. Another study reported the treatment of twenty-two patients with metastatic melanoma with the BOLD scheme every four weeks, together with IFN- $\alpha 3 \times 10^{6}$ IU daily for six weeks, followed by $6 \times 10^{6} \mathrm{IU}$ three times per week. This treatment showed median progression-free survival of four months and median overall survival of 12 months, associated with moderate toxicity [137]. A similar scheme was used in a study reported by Atzpodien et al. (2002) [125], in which the median progression-free survival was 1.9 months and overall survival 10.6 months, but the scheme showed more toxicity in $13 \%$ of the patients (alopecia and neurotoxicity). The regimen of BOLD plus interferon is active in the treatment of metastatic uveal melanoma. The precise role of the regimen has to be defined in light of its toxicity, particularly the unpredictable pulmonary toxicity. The pattern of occurrence of these pulmonary events is most consistent with either an acquired hypersensitivity reaction, or a cumulative toxic effect from two or more agents. Patients considered for treatment with this regimen must be judiciously selected. Those with no clear contraindications may benefit from a trial of this regimen, but they must be monitored closely.

Another regimen that has shown good results was the combination of bleomycin $15 \mathrm{mg}$ administered subcutaneously on days one and four, vindesine $3 \mathrm{mg} / \mathrm{m}^{2}$ administered intravenously on days one and five and lomustine $80 \mathrm{mg} / \mathrm{m}^{2}$ orally on day one and dacarbazine 
$200 \mathrm{mg} / \mathrm{m}^{2}$ intravenously on days one through five in a phase III study. This combined response rate of $45 \%$ is considerably better than that seen in single- or dual-agent chemotherapy. The toxicity was tolerable. The median survival for all treated patients was 43 weeks, and the median follow-up time was now 63 weeks [139]. Stables et al. (1992) [140] evaluated the treatment of 72 patients with melanoma with a regime combination including bleomycin, vindesine, lomustine and dacarbazine. This study showed a complete response in $17.6 \%$ of the patients, partial response in $14.7 \%$ of the patients and overall median survival of 38 weeks. These results are comparable with other combinations of chemotherapy regimens, which have not yet been supplanted by the newer biological therapies.

Based on the independent activity of cisplatin, vinblastine, and dacarbazine (CVD), a combination of these agents was used in the treatment of patients with advanced melanoma. Different doses are used in this treatment scheme, but the most common combination is vinblastine in a dose of $1.6 \mathrm{mg} / \mathrm{m}^{2} / \mathrm{d}$ for five days, dacarbazine in a dose of $800 \mathrm{mg} /$ $\mathrm{m}^{2}$ intravenously on day one, and cisplatin in a dose of $20 \mathrm{mg} / \mathrm{m}^{2} / \mathrm{d}$ for four days starting on day two of chemotherapy or, 3-week cycles of cisplatin $20 \mathrm{mg} / \mathrm{m}^{2} /$ day x 4; vinblastine $2 \mathrm{mg} / \mathrm{m}^{2} /$ day $\times 4$, and dacarbazine $800 \mathrm{mg} / \mathrm{m}^{2}$ on day one [141]. In a phase II trial with 50 evaluable patients, a response rate of $40 \%$ was achieved with an estimated 1-year survival of $50 \%$ [141]. In a randomized trial using biochemotherapy, in which CVD was the control arm, the same investigators reported that CVD showed an objective response rate of $27 \%$ and an estimated 1-year survival of approximately $40 \%$ [142]. The median duration of the response was nine months and the median survival time of the responders was 12 months. The treatment was associated with significant toxicity consisting of nausea, vomiting, diarrhoea and partial hair loss. Additionally, neutropenia with a median nadir granulocyte count of 500/microliters was observed, and significant anaemia required blood transfusions in a majority of the patients after three to four courses of chemotherapy. The dose-limiting toxicity was peripheral neuropathy, which required discontinuation of cisplatin after six to eight courses of chemotherapy [141].

Another study used a combination of dacarbazine $250 \mathrm{mg} / \mathrm{m}^{2} /$ day one to three, cisplatin 30 $\mathrm{mg} / \mathrm{m}^{2} /$ day i.v. on days one to three and IFN- $\alpha 10 \times 10^{6} \mathrm{U} / \mathrm{m}^{2} /$ day subcutaneously on days one to five, and one group received the combination mentioned, plus IL-2 as a continuous i.v. infusion in a decreasing schedule starting on day 5 with 18 million $\mathrm{U} / \mathrm{m}^{2}$ over 6 hours followed by 18 million $\mathrm{U} / \mathrm{m}^{2}$ over 12 hours, 18 million $\mathrm{U} / \mathrm{m} 2$ over 24 hours, and a maintenance dose of 4.5 million $\mathrm{U} / \mathrm{m}^{2} / 24$ hours for an additional 72 hours. Cycles were repeated every four weeks for a maximum of four cycles. This study showed that the combination was not better than the CVD combination, and was associated with low efficacy and higher toxicity. The authors concluded that the combination neither conferred a clinically meaningful survival benefit for most patients with advanced melanoma, nor conferred an increase in rate response or progression time [94].

Another study has shown results related to the treatment of patients with metastatic melanoma with six concurrent biochemotherapy dose levels. The doses were programed as follows: dacarbazine $800 \mathrm{mg} / \mathrm{m}^{2}$ or $1000 \mathrm{mg} / \mathrm{m}^{2}$ (Day 1); cisplatin $25 \mathrm{mg} / \mathrm{m}^{2}$ or $30 \mathrm{mg} / \mathrm{m}^{2}$ (Days 1-4); vinblastine $1.6 \mathrm{mg} / \mathrm{m}^{2}$ or $1.8 \mathrm{mg} / \mathrm{m}^{2}$ (Days 1-5); interleukin-2 9 million units (MU) per $\mathrm{m}^{2}$ or 12 
$\mathrm{MU} / \mathrm{m}^{2}$ as a $24 \mathrm{~h}$ continuous infusion (Days 1-4); and interferon-alpha-2b $5 \mathrm{MU} / \mathrm{m}^{2}, 10$ $\mathrm{MU} / \mathrm{m}^{2}$, or $15 \mathrm{MU} / \mathrm{m}^{2}$ (Days 1-5) and $5 \mathrm{MU} / \mathrm{m}^{2}$ (Days 7, 9, and 11) administered subcutaneously. The dose of IFN- $\alpha$ was reduced in some patients because of thrombocytopenia after five days, and other toxic effects observed included encephalopathy, renal and hepatic dysfunction, pancreatitis and ileus. This treatment showed a median time to disease progression of 6.9 months, and median survival duration of 12.2 months [143]. In a study reported by Legha et al. (1996) [90] e treatment with CVD plus IL-2 or IFN- $\alpha$ reached an overall response rate of $60 \%$, although the duration of partial response was short (median eight months), the median survival of patients receiving sequential biochemotherapy was 13 months compared to nine months observed in the CVD treated group. The treatment with biochemotherapy was associated with severe toxicity including intense myelosuppression, infections; IL-2 induced constitutional toxicity and hypotension. The biochemotherapy regimen produced an apparent increase in the median survival compared to that observed with the CVD regimen.

In a randomized study, 176 patients received cisplatin and dacarbazine with or without carmustine every 21 days, or the same regimen followed by low-dose subcutaneous IL-2 for eight days and IFN- $\alpha$ three times a week, both for six cycles. The regimen without IL-2 and IFN- $\alpha$ resulted in a median overall survival of 9.5 months and the regimen with IL-2 and IFN$\alpha$ of 11.0 months. The regimen with low-dose immunotherapy did not produce a statistically significant advantage in overall survival, time to progression or overall response when compared with the regimen without immunotherapy. However, the results were not different from the treatment with high dose IL-2 [87].

In a phase III study, 326 patients with metastatic melanoma received the treatment consisting of a combination of dacarbazine ( $250 \mathrm{mg} / \mathrm{m}^{2}$ intravenously days one to five every four weeks) and vindesine $\left(3 \mathrm{mg} / \mathrm{m}^{2}\right.$ intravenously day one weekly), with or without the addition of cisplatin $\left(100 \mathrm{mg} / \mathrm{m}^{2}\right.$ intravenously day one every four weeks). In this study the authors did not observe a significant difference in overall survival with addition of cisplatin, but the median time to progression was significantly longer in patients treated with dacarbazine, vindesine and cisplatin than patients that did not receive cisplatin (4.2 versus 2.2 months respectively). However, the combination of the three drugs did not change overall survival but did significantly increase toxicity such as leukopenia, alopecia and nausea/vomiting [144]. Similar treatment was used in a phase II study with forty patients with disseminated malignant melanoma. In this study, the authors observed a 38\% response rate and median response duration of four months, but the toxicity was intolerable with symptoms such as nephrotoxicity, ototoxicity, hypotonia and nausea/vomiting [126].

Fotemustine has also been used in combination with dacarbazine, in patients with metastatic melanoma. The response rate was $27.2 \%$, confirming the activity of fotemustine. The combination of two drugs showed significant toxicity, mainly haematological with leukopenia and thrombocytopenia. This schedule with sequential dacarbazine and fotemustine had low activity against metastatic melanoma, and the response rate for cerebral metastases was not superior to that shown in other studies with single agent fotemustine, however, the treatment was well tolerated and can be prescribed to outpatients [54]. 
Preclinical studies have shown some clinical activity against melanoma. It consisted of a combination of carboplatin at an area under the curve (AUC) of 7.5 and paclitaxel at 175 $\mathrm{mg} / \mathrm{m}^{2}$ over three hours administered to 17 patients [127]. There was a $20 \%$ response rate with three partial responders in the 15 evaluable patients, with a median survival of nine months. Another phase II study showed results with the administration of paclitaxel either as monotherapy or combined with carboplatin. In the first treatment paclitaxel was administered at a dose of $100 \mathrm{mg} / \mathrm{m}^{2}$ intravenously on day one each week for six weeks; in the second treatment paclitaxel was administered at a dose of $80 \mathrm{mg} / \mathrm{m}^{2}$ intravenously followed by carboplatin 200 $\mathrm{mg} / \mathrm{m}^{2}$ on day one each week for six weeks. The next cycle was administered after a two-week intermission. This study showed median survival time of 209 days in patients that received only paclitaxel, and 218 days for those treated with paclitaxel/carboplatin, with overall response rates of less than $10 \%$ for both treatments [68]. Paclitaxel at a dose of $100 \mathrm{mg} / \mathrm{m}^{2}$ and carboplatin of 2 AUC was administered on days one, eight and 15 of a 28 day cycle. This treatment showed $26 \%$ partial response and $19 \%$ stable disease and a median overall survival of 7.8 months [128].

Kottschade et al. (2011) [148] conducted a study in which the patients were treated with paclitaxel $100 \mathrm{mg} / \mathrm{m}^{2}$ and carboplatin AUC six administered on days one, eight and 15 every 28 days. The median number of treatment cycles was four. This treatment showed $25.6 \%$ responses and median overall survival of 11.1 months. In a study conducted by Pflugfelder et al. (2011) [149], patients received intravenous paclitaxel $225 \mathrm{mg} / \mathrm{m}^{2}$ plus intravenous carboplatin AUC 6 on day one of a 21 day cycle, with a dose reduction after the fourth cycle to carboplatin AUC five and paclitaxel $175 \mathrm{mg} / \mathrm{m}^{2}$. This study showed median progression-free survival of 10 weeks and median overall survival of 31 weeks. Response, progression-free, and overall survival were equivalent in first and second line patients. Sixty patients out of 61 died after a median follow-up of seven months. This treatment showed, in all studies, severe toxicities including neutropenia, thrombocytopenia, neurosensory problems, fatigue, nausea and vomiting $[68,127,129]$.

The development of targeted therapies has provided new options for the management of patients with advanced melanoma. There has been particular interest in agents that target the mitogen-activated protein kinase pathway, which controls tumor growth and survival, and promotes angiogenesis. Recently, sorafenib, an oral multikinase inhibitor has been tested in combination with carboplatin and paclitaxel. A phase I trial conducted with 38 patients, who received either 100, 200, or $400 \mathrm{mg}$ of sorafenib twice daily on days 2 to 19 of a 21-day cycle with carboplatin at AUC 6 and paclitaxel at $225 \mathrm{mg} / \mathrm{m}^{2}$ administered on day one [130]. The overall response was 10 out of 24 treated patients with one complete response. Another study, however, showed that the treatment of 270 patients with paclitaxel at $225 \mathrm{mg} / \mathrm{m}^{2}$ and carboplatin at AUC 6 once every three weeks with or without sorafenib at $400 \mathrm{mg}$ twice daily on days two to 19. There was no difference in progression-free survival, which was the primary endpoint, or in response rate [131]. The control group (no sorafenib) showed a response rate of $11 \%$ with a median progression-free survival of 17.4 weeks; the median overall survival was 42 weeks. The cohort receiving sorafenib had essentially identical outcomes. The conclusion 
was that the addition of sorafenib to carboplatin/paclitaxel did not improve the response rate in contrast to the original observations in the phase I trial [130].

Recently, patients were randomly assigned in a two-to-one ratio to carboplatin (AUC, 5) plus paclitaxel $\left(175 \mathrm{mg} / \mathrm{m}^{2}\right)$ and bevacizumab $(15 \mathrm{mg} / \mathrm{kg})$ administered intravenously once every three weeks. This study showed an overall response rate of $25.5 \%$. The study did not meet the primary objective of statistically significant improvement in median survival with the addition of bevacizumab to carboplatin plus paclitaxel. A larger phase III study will be necessary to determine whether there is any benefit to the addition of bevacizumab to carboplatin plus paclitaxel in this disease setting [132].

Schmittel et al. (2006) [133] compared the combination of gemcitabine plus treosulfan with treosulfan alone in patients with metastatic melanoma; the patients received $1000 \mathrm{mg} / \mathrm{m}^{2}$ of gemcitabine plus $3500 \mathrm{mg} / \mathrm{m}^{2}$ of treosulfan or $3500 \mathrm{mg} / \mathrm{m}^{2}$ of treosulfan on days one and eight, and in both groups the cycle was repeated on day 29. Median progression-free survival was three months and two months for patients undergoing the treatment with gemcitabine plus treosulfan and treosulfan, respectively. In a phase II clinical trial, gemcitabine plus treosulfan were tested in patients with metastatic melanoma. The patients received $1000 \mathrm{mg} / \mathrm{m}^{2}$ of gemcitabine and treosulfan at a dose of 2500 or $3000 \mathrm{mg} / \mathrm{m}^{2}$ in group one, and 3500 or 4000 $\mathrm{mg} / \mathrm{m}^{2}$ in group two on days one and eight every four weeks. In the group of patients that were treated with treosulfan in a dose less or equal to $3000 \mathrm{mg} / \mathrm{m}^{2}$, the response rate was not observed. Among the patients treated with a dose equal to or more than $3500 \mathrm{mg} / \mathrm{m}^{2}$ a $5 \%$ partial remission was observed, with median survival time of nine months [134]. Another study by Schmittel et al. (2005) [154] combined gemcitabine plus treosulfan and cisplatin, in which the patients received 30 or $40 \mathrm{mg} / \mathrm{m}^{2}$ of cisplatin, $1000 \mathrm{mg} / \mathrm{m}^{2}$ of gemcitabine and 3000 $\mathrm{mg} / \mathrm{m}^{2}$ of treosulfan on days one and eight repeated on day 29 ; the median overall survival was 7.7 months, associated with excessive haematological toxicity.

Dacarbazine $250 \mathrm{mg} / \mathrm{m}^{2} /$ day was combined with epirubicin $90 \mathrm{mg} / \mathrm{m}^{2}$ on day one every three weeks. Partial response of $21.1 \%$ was observed [135].

Another phase III study of ipilimumab was carried out in patients with previously untreated metastatic melanoma. In this case, ipilimumab in combination with dacarbazine was compared with dacarbazine plus placebo, showing improved overall survival with the antibody therapy. Responses with the combined therapies seemed to be higher than the therapies with a single agent (17\% compared to 5\%) [105]. Data from preclinical and clinical studies have shown that ipilimumab can cause tumor regression in patients with metastatic melanoma with response rates of $5.8-22 \%$. Phase III trials have demonstrated a benefit to median overall survival in the first-line setting in combination with dacarbazine versus dacarbazine alone (11.2 versus 9.1 months), and in the second-line setting in combination with glycoprotein 100 peptide vaccine (gp100) vs. gp100 alone (10.1 versus 6.4 months). The main toxicities of ipilimumab are immune related, most commonly skin and gastrointestinal troubles. Bowel perforation and treatmentrelated deaths have occurred, although prompt use of steroids and other immunosuppressive agents can minimize these risks [136]. 
In phase II study patients with metastatic melanoma received ipilimumab at three $\mathrm{mg} / \mathrm{kg}$ every four weeks for four doses, either alone or with up to six-five-day courses of dacarbazine 250 $\mathrm{mg} / \mathrm{m}^{2} /$ day. The response rate was $14.3 \%$ with ipilimumab plus dacarbazine and median overall survival was 14.3 months [137].

\section{News strategies for treatment of metastatic melanoma}

\subsection{Signalling molecules targeted therapy}

One of the most common signalling pathways affected by mutations in melanoma is the RAF/ MEK/ERK pathway, a highly conserved group of proteins that regulate cell growth, division and death. In melanoma, the most common mutations are in proteins like BRAF, NRAS, HRAS, and KIT and lead to constitutive activation of the RAF/MEK/ERK pathway, which stimulates pro-proliferative genes. BRAF, the serine/threonine specific protein kinase, is triggered by somatic mutations in $50-70 \%$ of melanoma cases. A substitution of glutamic acid for valine at codon 600 (V600E) is the most common BRAF mutation known [138]. Recently, genotypeselected metastatic melanoma patients with positive BRAF mutation have been submitted to clinical trials with drabafenib (accelerated dose titration with $12 \mathrm{mg}$ initial dose), an inhibitor of BRAF kinase, selective for mutations in BRAF. High response rates were achieved in patients with melanoma brain metastases leading to nine out of ten patients with a size reduction of brain lesions [139]. A phase III trial comparing drabafenib (150 mg twice daily, orally) with dacarbazine (1000 mg/m² intravenously every 3 weeks), higher median progression-free survival was observed in the drabafenib group than those for dacarbazine. However, dose reduction of drabafenib was needed in $28 \%$ of patients due to adverse effects including nausea, vomiting, fatigue and neutropenia. Dose reduction was also necessary in patients receiving dacarbazine (17\%) [131].

Despite these front line studies that validated BRAF inhibition and genotyping analysis of BRAF mutational status as a feasible tool in patients undergoing clinical trials with signalling molecules targeted therapy, side effects remain the most important concern during therapy. In this field, another BRAF inhibitor, vemurafenib, was compared to dacarbazine, and studies demonstrated that vemurafenib-treated patients had higher overall survival rate and final analysis for progression-free survival than those who received dacarbazine. Also, the vemurafenib-treated group had relative reduction of $63 \%$ in the risk of death and of $74 \%$ in the risk of either death or disease progression, as compared to dacarbazine. Regarding adverse effects, $18 \%$ of patients treated with vemurafenib presented cutaneous squamous-cell carcinoma, keratoacanthoma, or both [10].

However, after genetic status assessment, Falchook et al. (2012) [140] demonstrated that trametinib, a reversible selective allosteric inhibitor of MEK1 and MEK2, had a good clinical activity in patients with melanoma, suggesting that MEK could be a valid therapeutic target in BRAF-mutant melanoma. Interestingly, patients were free of proliferative skin lesions such as squamous-cell carcinoma, a common adverse effect associated with BRAF inhibitors, representing an advantage of trametinib in treating early-stage diseases [140]. 
With regard to drug resistance, antiapoptotic proteins of the Bcl-2 family are closely involved in this process. This group of proteins regulates apoptosis by blocking the release of cytochrome $c$ and the overexpression of $\mathrm{Bcl}-2$, which has been partially associated with drug resistance phenomena (Soengas et al., 2003). In this field, antisense Bcl-2 therapy may be an alternative coadjutant therapy in melanoma clinical trials. In the past, in vitro experimental transfection of Bcl-2 was performed in both haematological and solid tumor cells, leading to multidrug resistant phenotype [141] and recently, oblimersen sodium was combined with dacarbazine in a clinical trial involving 771 patients with advanced melanoma [13]. This new drug decreased the expression of Bcl-2 protein by increasing the cleavage of Bcl-2 mRNA by RNase H [142,143].

Another mechanism of tumor resistance is related to the repair process of damaged DNA. The poly (ADP-ribose) polymerase-1 (PARP) is the nuclear key enzyme of this process and mediates the recruitment and activation of repair factors in the DNA break leading to base excision repair [144]. The first phase I clinical trial with inhibitor of PARP was conducted with AG014699, a prodrug of AG014447, a potent inhibitor of PARP, combined with temozolomide in patients with solid tumors and metastatic melanoma. In this clinical trial, AG014699 was well tolerated and proved to be highly and selectively toxic to cells that underwent DNA repair [145].

Finally, one of the most studied signalling molecules is NF- $\kappa \mathrm{B}$, a pathway that melanoma cells use to increase survival, proliferation and resistance to apoptosis, leading to progression of tumor and metastasis appearance $[146,147]$. One of the first NF- $\kappa B$ inhibitors used in clinical trials was bortezomib. Combined with temozolomide, a phase I clinical trial was conducted in order to establish a schedule use of these drugs, define phase II doses and assess the NF- $\kappa \mathrm{B}$ activity in blood. Results demonstrated that bortezomib failed to inhibit NF- $\kappa B$, and toxicities including neurotoxicity, fatigue, diarrhoea and rash were reported [18]. Furthermore, two years later another phase I trial with patients with advanced solid tumors was conducted in order to establish new maximum tolerated doses for the combination of bortezomib and temozolomide with inconclusive results [148]. In addition, both groups of authors suggested that new studies with strong preclinical rationale have to be conducted in order to cover all the changes undergone at tumor sites $[18,148]$.

\subsection{Electrochemotherapy}

After years of experience in delivering genes, DNA and drugs into mammalian cells using electroporation [149,150], a local tumor ablation modality, the electrochemotherapy (ECT) has been used effectively in the treatment of various solid tumors, particularly melanoma. ECT combines chemotherapy and electroporation to increase drug uptake into cancer cells [151]. The European Standard Operating Procedures of Electrochemotherapy (ESOPE) was the largest study reported so far in patients with melanoma [152]. In this huge clinical trial, the efficacy and safety of ECT were evaluated according to the drug used, route of administration and types of electrodes for electroporation. The ESOPE project consisted of the administration of bleomycin (ineffective for systemic conventional therapy), both intravenously (15000 $\mathrm{IU} / \mathrm{m}^{2}$ ) and intratumorally $\left(1000 \mathrm{IU} / \mathrm{cm}^{3}\right)$, followed by eletroportation. Cisplatin was also 
administered in some patients (only intratumorally), because previous reports had not substantiated the high efficacy of electrochemotherapy using intravenous injection of cisplatin [153]. Almost $74 \%$ of patients had complete response rate achieved on the electrochemotherapy treated tumor nodules. Furthermore, side effects were minor and acceptable by patients and showed great advantages regarding cost and effectiveness.

Recently, another approach using ECT, based on the ESOPE study, has been conducted in patients with cutaneous and subcutaneous melanoma metastases. Bleomycin was also used as a drug of choice for most cases, and ECT was conducted after intravenous administration of bleomycin $\left(15 \mathrm{mg} / \mathrm{m}^{2}\right)$. Results demonstrated that $62 \%$ of patients had an objective response rate for all treated metastases. The authors also observed that $23 \%$ of patients had complete response of metastatic nodules and only $8 \%$ of patients showed disease progression. Because ECT was achieved using low doses of bleomycin, no systemic side effects were observed [154].

Regarding disseminated superficial metastasis, Campana et al. (2012) [175] demonstrated that several ECT cycles on metastases, unsuitable for resection or unresponsive to conventional chemotherapy, were effective only in patients with few and small metastases on the lower limb. Besides the restricted response, ECT was well tolerated and side effects were limited.

\subsection{Transarterial chemoembolization}

In an attempt to manage metastatic melanoma, especially liver metastases, new approaches have been tested using the dual blood vessels supply of the liver in combination with anticancer drugs such as irinotecan and cisplatin. This new approach, the so-called transarterial chemoembolization (TACE), takes therapeutic advantage of the hepatic artery and branches of the portal vein. By infusing chemotherapeutic agents directly into vessels followed by infusion of embolic microspheres, localized therapy and the concentration of the drug in tumor are achieved. In this field, Venturini et al. (2012) [155] enrolled five chemotherapy-naive patients with liver metastasis of uveal melanoma in an irinotecan-eluting chemoembolization trial. TACE was successfully achieved and well-tolerated in all five patients. In addition, a response rate of $80 \%$ was achieved in relation to lesion size and remission. Apart from local pain and one isolated case of cholecystitis, no further side effects were observed.

In a more complex study design including cisplatin, carboplatin, fotemustine or melphalan infusion followed by polyvinyl alcohol particles for embolization, 11 patients were monitored for five to 58 months, and $57 \%$ of them presented partial response compared to $29 \%$ with stable disease, and $14 \%$ presented new lesions detected during the follow up period. Median survival of all patients was 11.5 months after metastasis diagnosis [156]. In addition, abdominal and local pain seems to be the most common effect after TACE procedures. Huppert et al. (2010) [177] reported that pain began 1-4h after embolization and lasted around one to three days, and that morphine was necessary in some cases.

Transarterial chemoembolization has the advantages of reducing systemic toxicity of drugs and increasing intratumor effects leading to better results. However, Schusser et al. (2010) [178] also reported serious side effects after TACE protocol using fotemustin $\left(100 \mathrm{mg} / \mathrm{m}^{2}\right)$ as a 
first choice, followed by cisplatin (50 mg), including splenic infarction, thrombocytopenia and gastric ulcer; all events required conservative treatment and prolonged hospitalization.

\subsection{Adoptive T cells therapy}

Immunotherapy has been widely reported as a promising alternative for a variety of malignancies including melanoma [157]. To divert the majority of the immune cells to react against tumor has been a huge challenge among physicians. Particularly, adoptive T cells (ATC) optimally expanded ex-vivo, in theory, could enhance anti-tumor immune response and form memory protection against recurrence. A well-established expansion of tumor-infiltrating lymphocytes (TIL) has been carefully used in clinical trials, especially in metastatic melanoma patients [79,158-160]. Recently, 93 patients with metastatic melanoma were treated with the ATC transfer of autologous TIL and IL-2 with a median follow-up of 62 months. $22 \%$ of patients showed complete regression and durable complete responses were seen in patients who had a median of three different organ sites of metastases including lung, liver, adrenal, muscle, lymphonodes, and skin [161]. However, some limitation was observed in ATC therapy. Joseph et al. (2011) [184] reported a negative influence in initial TIL outgrowth in samples obtained from patients who received systemic therapy 30 days before tumor harvest. This data suggested that parameters like prior systemic chemotherapy should be considered as important criteria for patients undergoing ATC therapy. The success of autologous TIL derived from metastatic tumor tissue is dependent on the TIL initial outgrowth and the tumor characteristics, rate of TIL and parallel systemic chemotherapy, because the latter determines the rate of TIL harvested [162].

In an attempt to make up for some limitations of ATC therapy, especially those related to TIL harvested outgrowth and based on the observation that melanoma-reactive TIL could be generated from only 50\% of harvested samples [163], autologous T cells transduction with T-cell receptors (TCR) against the antigen NY-ESO-1 was carried out. A retroviral vector encoding a TCR, which recognizes the peptide NY-ESO-1, an antigen highly expressed in almost $50 \%$ of melanoma metastases, was transfected into T-cells of patients, cultured ex-vivo and transferred to patients together with HD IL-2, as a complementary therapy. Results from this vanguard clinical trial showed that five of the 11 patients with metastatic melanoma experienced an objective response including two complete responses during the follow-up period (20 months), and 2 patients demonstrated complete regressions that persisted after one year.

\section{Insights in side effects prevention}

It is clear that the cure for malignant melanoma is still a challenge. One can conceive of many strategies to combat the disease: i) prevention ii) several kinds of therapies, iii) amelioration of side effects caused by the therapies. In this regard, there is evidence that natural or semisynthetic compounds can feasibly allow for a wide variety of potential drugs to be employed in a multitarget approach alone and/or in combined therapies. 
Syed and Muktar (2011) [164] summarized some options in a review article about several plant products for the prevention and treatment of different kinds of cancer, including melanoma. Among the compounds they mentioned: genistein, epigallocatechin gallate, resveratrol, curcumin, fisetin, silymarin lupeol, which are able to stop the growth of tumor cells through their own multitarget drug properties [164]. In the same context, several research groups, including ours, have studied gallic acid and its ester derivatives [165-168]. It has been shown that gallic acid and gallates differing only in the number of carbon atoms in the lateral chain present antitumor properties, whose mechanism of action is also by a multitarget way, including cell growth and metastasis inhibition, action against the drug efflux, helping to avoid the development of resistance as well as a selective cytotoxicity

\section{Conclusion}

Significant advancements have been made in the last few years about melanoma treatment, including important information on the molecular mechanism of action of the drugs and the signalling pathways related to the disease. However, the treatment of patients with advanced melanoma remains unsatisfactory. Single agent or combinations of chemotherapies including new agents or biologic response modifiers have not resulted in response rates of durable remissions high enough to affect median survival. The approval by the FDA of ipilimumab in 2011 brought some optimism among the clinicians who treat patients with metastatic melanoma, but this therapy also has its limitations.

Promising sources of alternative molecules for cancer seem to be plants. In general, natural or semi-synthetic compounds have shown effectiveness not only in the prevention of the disease and the development of resistance, but also in important antitumoral activities in vitro and in pre-clinical assays.

\section{Author details}

Claudriana Locatelli ${ }^{1}$, Fabíola Branco Filippin-Monteiro² and Tânia Beatriz Creczynski-Pasa ${ }^{2}$

1 Biology and Health Sciences, Universidade do Oeste de Santa Catarina,UNOESC, Videira, Brazil

2 Pharmaceutical Sciences Departament, Universidade Federal de Santa Catarina, UFSC, Florianópolis, Brazil

\section{References}

[1] de Vries E, Bray FI, Coebergh JW, Parkin DM. Changing epidemiology of malignant cutaneous melanoma in Europe 1953-1997: rising trends in incidence and mortality 
but recent stabilizations in western Europe and decreases in Scandinavia. Int J Cancer 2003;107:119-126.

[2] Whiteman DC, Whiteman CA, Green AC. Childhood sun exposure as a risk factor for melanoma: a systematic review of epidemiologic studies. Cancer Causes Control 2001;12:69-82.

[3] Bressac-de-Paillerets B, Avril MF, Chompret A, Demenais F. Genetic and environmental factors in cutaneous malignant melanoma. Biochimie 2002;84:67-74.

[4] Balch CM, Buzaid AC, Soong SJ, Atkins MB, Cascinelli N, Coit DG, et al. Final version of the American Joint Committee on Cancer staging system for cutaneous melanoma. Journal of Clinical Oncology 2001;19.

[5] Monzon JG, Dancey J. Targeted agents for the treatment of metastatic melanoma. Oncotargets and Therapy 2012;5.

[6] Jemal A, Siegel R, Ward E, Hao Y, Xu J, Murray T, et al. Cancer statistics, 2008. CA Cancer J Clin 2008;58:71-96.

[7] Mouawad R, Sebert M, Michels J, Bloch J, Spano JP, Khayat D. Treatment for metastatic malignant melanoma: old drugs and new strategies. Crit Rev Oncol Hematol 2010;74:27-39.

[8] Bhatia S, Tykodi SS, Thompson JA. Treatment of metastatic melanoma: an overview. Oncology (Williston Park) 2009;23:488-496.

[9] Nashan D, Müller ML, Grabbe S, Wustlich S, Enk A. Systemic therapy of disseminated malignant melanoma: an evidence-based overview of the state-of-the-art in daily routine. J Eur Acad Dermatol Venereol 2007;21:1305-1318.

[10] Chapman PB, Hauschild A, Robert C, Haanen JB, Ascierto P, Larkin J, et al. Improved survival with vemurafenib in melanoma with BRAF V600E mutation. N Engl J Med 2011;364:2507-2516.

[11] Strumberg D, Clark JW, Awada A, Moore MJ, Richly H, Hendlisz A, et al. Safety, pharmacokinetics, and preliminary antitumor activity of sorafenib: a review of four phase I trials in patients with advanced refractory solid tumors. Oncologist 2007;12:426-437.

[12] Bartlett JB, Michael A, Clarke IA, Dredge K, Nicholson S, Kristeleit H, et al. Phase I study to determine the safety, tolerability and immunostimulatory activity of thalidomide analogue CC-5013 in patients with metastatic malignant melanoma and other advanced cancers. Br J Cancer 2004;90:955-961.

[13] Bedikian AY, Millward M, Pehamberger H, Conry R, Gore M, Trefzer U, et al. Bcl-2 antisense (oblimersen sodium) plus dacarbazine in patients with advanced melanoma: the Oblimersen Melanoma Study Group. J Clin Oncol 2006;24:4738-4745. 
[14] Tarhini AA, Kirkwood JM. Oblimersen in the treatment of metastatic melanoma. Future Oncol 2007;3:263-271.

[15] Atkins M, Lee S, Flaherty L, Sosman J, Sondak V, Kirkwood J. A prospective randomized phase III trial of concurrent biochemotherapy (BCT) with cisplatin, vinblastine, dacarbazine (CVD), IL-2 and interferon alpha-2b (IFN) versus CVD alone in patients with metastatic melanoma (E3695): An ECOG-coordinated intergroup trial. Proc Am Soc Clin Oncol, 2003.

[16] Burke JR, Pattoli MA, Gregor KR, Brassil PJ, MacMaster JF, McIntyre KW, et al. BMS-345541 is a highly selective inhibitor of I kappa B kinase that binds at an allosteric site of the enzyme and blocks NF-kappa B-dependent transcription in mice. Journal of Biological Chemistry 2003;278.

[17] Liu J, Suresh Kumar KG, Yu D, Molton SA, McMahon M, Herlyn M, et al. Oncogenic BRAF regulates beta-Trcp expression and NF-kappaB activity in human melanoma cells. Oncogene 2007;26:1954-1958.

[18] Su Y, Amiri KI, Horton LW, Yu Y, Ayers GD, Koehler E, et al. A phase I trial of bortezomib with temozolomide in patients with advanced melanoma: toxicities, antitumor effects, and modulation of therapeutic targets. Clin Cancer Res 2010;16:348-357.

[19] Pisano M, Pagnan G, Dettori MA, Cossu S, Caffa I, Sassu I, et al. Enhanced anti-tumor activity of a new curcumin-related compound against melanoma and neuroblastoma cells. Mol Cancer 2010;9:137.

[20] Yang AS, Chapman PB. The history and future of chemotherapy for melanoma. Hematol Oncol Clin North Am 2009;23:583-597, x.

[21] Garbe C, Radny P, Linse R, Dummer R, Gutzmer R, Ulrich J, et al. Adjuvant lowdose interferon \{alpha\}2a with or without dacarbazine compared with surgery alone: a prospective-randomized phase III DeCOG trial in melanoma patients with regional lymph node metastasis. Ann Oncol 2008;19:1195-1201.

[22] Meer L, Janzer RC, Kleihues P, Kolar GF. In vivo metabolism and reaction with DNA of the cytostatic agent, 5-(3,3-dimethyl-1-triazeno)imidazole-4-carboxamide (DTIC). Biochem Pharmacol 1986;35:3243-3247.

[23] Luce JK, Thurman WG, Isaacs BL, Talley RW. Clinical trials with the antitumor agent 5-(3,3-dimethyl-1-triazeno)imidazole-4-carboxamide(NSC-45388). Cancer Chemother Rep 1970;54:119-124.

[24] Costanza ME, Nathanson L, Lenhard R, Wolter J, Colsky J, Oberfield RA, et al. Therapy of malignant melanoma with an imidazole carboxamide and bis-chloroethyl nitrosourea. Cancer 1972;30:1457-1461.

[25] Nathanson L, Wolter J, Horton J, Colsky J, Shnider BI, Schilling A. Characteristics of prognosis and response to an imidazole carboxamide in malignant melanoma. Clin Pharmacol Ther 1971;12:955-962. 
[26] Middleton MR, Grob JJ, Aaronson N, Fierlbeck G, Tilgen W, Seiter S, et al. Randomized phase III study of temozolomide versus dacarbazine in the treatment of patients with advanced metastatic malignant melanoma. J Clin Oncol 2000;18:158-166.

[27] Howe HL, Wingo PA, Thun MJ, Ries LA, Rosenberg HM, Feigal EG, et al. Annual report to the nation on the status of cancer (1973 through 1998), featuring cancers with recent increasing trends. J Natl Cancer Inst 2001;93:824-842.

[28] Eggermont AM, Kirkwood JM. Re-evaluating the role of dacarbazine in metastatic melanoma: what have we learned in 30 years? Eur J Cancer 2004;40:1825-1836.

[29] Propper DJ, Braybrooke JP, Levitt NC, O'Byrne K, Christodoulos K, Han C, et al. Phase II study of second-line therapy with DTIC, BCNU, cisplatin and tamoxifen (Dartmouth regimen) chemotherapy in patients with malignant melanoma previously treated with dacarbazine. Br J Cancer 2000;82:1759-1763.

[30] Newlands ES, Blackledge GR, Slack JA, Rustin GJ, Smith DB, Stuart NS, et al. Phase I trial of temozolomide (CCRG 81045: M\&B 39831: NSC 362856). Br J Cancer 1992;65:287-291.

[31] Agarwala SS, Kirkwood JM. Temozolomide, a novel alkylating agent with activity in the central nervous system, may improve the treatment of advanced metastatic melanoma. Oncologist 2000;5:144-151.

[32] Friedman HS, Kerby T, Calvert H. Temozolomide and treatment of malignant glioma. Clin Cancer Res 2000;6:2585-2597.

[33] Bleehen NM, Newlands ES, Lee SM, Thatcher N, Selby P, Calvert AH, et al. Cancer Research Campaign phase II trial of temozolomide in metastatic melanoma. J Clin Oncol 1995;13:910-913.

[34] Robertson GP. Functional and therapeutic significance of Akt deregulation in malignant melanoma. Cancer Metastasis Rev 2005;24:273-285.

[35] VanBrocklin MW, Verhaegen M, Soengas MS, Holmen SL. Mitogen-activated protein kinase inhibition induces translocation of Bmf to promote apoptosis in melanoma. Cancer Res 2009;69:1985-1994.

[36] Biswas G, Bhagwat R, Khurana R, Menon H, Prasad N, Parikh PM. Brain metastasis-evidence based management. J Cancer Res Ther 2006;2:5-13.

[37] Chang JE, Robins HI, Mehta MP. Therapeutic advances in the treatment of brain metastases. Clin Adv Hematol Oncol 2007;5:54-64.

[38] Platta CS, Khuntia D, Mehta MP, Suh JH. Current treatment strategies for brain metastasis and complications from therapeutic techniques: a review of current literature. Am J Clin Oncol 2010;33:398-407.

[39] Mehta MP, Paleologos NA, Mikkelsen T, Robinson PD, Ammirati M, Andrews DW, et al. The role of chemotherapy in the management of newly diagnosed brain meta- 
stases: a systematic review and evidence-based clinical practice guideline. J Neurooncol 2010;96:71-83.

[40] Margolin K, Atkins MB, Thompson JA, Ernstoff MS, Weber J, Flaherty L, et al. Temozolomide and whole brain irradiation in melanoma metastatic to the brain: a phase II trial of the Cytokine Working Group. Journal of Cancer Research and Clinical Oncology 2002;128.

[41] Atkins MB, Gollob JA, Sosman JA, McDermott DF, Tutin L, Sorokin P, et al. A phase II pilot trial of concurrent biochemotherapy with cisplatin, vinblastine, temozolomide, interleukin 2, and IFN-alpha $2 \mathrm{~B}$ in patients with metastatic melanoma. Clinical Cancer Research 2002;8.

[42] Paul MJ, Summers Y, Calvert AH, Rustin G, Brampton MH, Thatcher N, et al. Effect of temozolomide on central nervous system relapse in patients with advanced melanoma. Melanoma Res 2002;12:175-178.

[43] Rietschel P, Wolchok JD, Krown S, Gerst S, Jungbluth AA, Busam K, et al. Phase II study of extended-dose temozolomide in patients with melanoma. J Clin Oncol 2008;26:2299-2304.

[44] D'Atri S, Tentori L, Lacal PM, Graziani G, Pagani E, Benincasa E, et al. Involvement of the mismatch repair system in temozolomide-induced apoptosis. Mol Pharmacol 1998;54:334-341.

[45] Tang L, Tron VA, Reed JC, Mah KJ, Krajewska M, Li G, et al. Expression of apoptosis regulators in cutaneous malignant melanoma. Clin Cancer Res 1998;4:1865-1871.

[46] Soengas MS, Capodieci P, Polsky D, Mora J, Esteller M, Opitz-Araya X, et al. Inactivation of the apoptosis effector Apaf-1 in malignant melanoma. Nature 2001;409:207-211.

[47] Panka DJ, Atkins MB, Mier JW. Targeting the mitogen-activated protein kinase pathway in the treatment of malignant melanoma. Clinical Cancer Research 2006;12.

[48] Wang CY, Cusack JC, Liu R, Baldwin AS. Control of inducible chemoresistance: enhanced anti-tumor therapy through increased apoptosis by inhibition of NF-kappaB. Nat Med 1999;5:412-417.

[49] Lev DC, Ruiz M, Mills L, McGary EC, Price JE, Bar-Eli M. Dacarbazine causes transcriptional up-regulation of interleukin 8 and vascular endothelial growth factor in melanoma cells: a possible escape mechanism from chemotherapy. Mol Cancer Ther 2003;2:753-763.

[50] Ranson M, Hersey P, Thompson D, Beith J, McArthur GA, Haydon A, et al. Randomized trial of the combination of lomeguatrib and temozolomide compared with temozolomide alone in chemotherapy naive patients with metastatic cutaneous melanoma. J Clin Oncol 2007;25:2540-2545. 
[51] Quéreux G, Dréno B. Fotemustine for the treatment of melanoma. Expert Opin Pharmacother 2011;12:2891-2904.

[52] Avril MF, Aamdal S, Grob JJ, Hauschild A, Mohr P, Bonerandi JJ, et al. Fotemustine compared with dacarbazine in patients with disseminated malignant melanoma: a phase III study. J Clin Oncol 2004;22:1118-1125.

[53] Jacquillat C, Khayat D, Banzet P, Weil M, Fumoleau P, Avril MF, et al. FINAL Report of The French Multicenter Phase-II study of the nitrosourea fotemustine in 153 evaluable patients with disseminated malignant-melanoma including patients with cerebral metastases. Cancer 1990;66.

[54] Khayat D, Avril MF, Gerard B, Bertrand P, Bizzari JP, Cour V. Fotemustine - an overview of its clinical activity in disseminated malignant-melanoma. Melanoma Research 1992;2.

[55] Falkson CI, Falkson G, Falkson HC. Phase II trial of fotemustine in patients with metastatic malignant melanoma. Invest New Drugs 1994;12:251-254.

[56] Petit T, Janser JC, Petit JC. Complete remission seven years after treatment for metastatic malignant melanoma. Cancer 1996;78:571.

[57] Chang J, Atkinson H, A'Hern R, Lorentzos A, Gore ME. A phase II study of the sequential administration of dacarbazine and fotemustine in the treatment of cerebral metastases from malignant melanoma. Eur J Cancer 1994;30A:2093-2095.

[58] Turrisi G, Sozzi P, Marinozzi C, Clerico MA. Persistent thrombocytopenia during melanoma treatment with fotemustine. Melanoma Res 2006;16:543-544.

[59] Feun LG, Lee YY, Plager C, Papadopoulos N, Savaraj N, Charnsangavej C, et al. Intracarotid cisplatin-based chemotherapy in patients with malignant melanoma and central nervous system (CNS) metastases. Am J Clin Oncol 1990;13:448-451.

[60] Evans LM, Casper ES, Rosenbluth R. Phase II trial of carboplatin in advanced malignant melanoma. Cancer Treat Rep 1987;71:171-172.

[61] Mohammed MQ, Retsas S. Oxaliplatin is active in vitro against human melanoma cell lines: comparison with cisplatin and carboplatin. Anticancer Drugs 2000;11:859-863.

[62] Soulié P, Raymond E, Brienza S, Cvitkovic E. [Oxaliplatin: the first DACH platinum in clinical practice]. Bull Cancer 1997;84:665-673.

[63] Lutzky J, Nunez Y, Graham P. A phase II trial of oxaliplatin in patients with advanced melanoma. ASCO Annual Meeting Proceedings, 2006.

[64] Whitehead RP, Moon J, McCachren SS, Hersh EM, Samlowski WE, Beck JT, et al. A phase II trial of vinorelbine tartrate in patients with disseminated malignant melanoma and one prior systemic therapy - A Southwest Oncology Group Study. Cancer 2004;100. 
[65] Jimeno A, Hitt R, Quintela-Fandino M, Cortes-Funes H. Phase II trial of vinorelbine tartrate in patients with treatment-naive metastatic melanoma. Anti-Cancer Drugs 2005;16.

[66] Dancey J, Steward WP. The role of vindesine in oncology--recommendations after 10 years' experience. Anticancer Drugs 1995;6:625-636.

[67] Emmert S, Zutt M, Haenssle H, Neumann C, Kretschmer L. Inefficacy of vindesine monotherapy in advanced stage IV malignant melanoma patients previously treated with other chemotherapeutic agents. Melanoma Res 2003;13:299-302.

[68] Retsas S, Newton KA, Westbury G. Vindesine as a single agent in the treatment of advanced malignant melanoma. Cancer Chemother Pharmacol 1979;2:257-260.

[69] Einzig AI, Schuchter LM, Recio A, Coatsworth S, Rodriquez R, Wiernik PH. Phase II trial of docetaxel (Taxotere) in patients with metastatic melanoma previously untreated with cytotoxic chemotherapy. Med Oncol 1996;13:111-117.

[70] Wiernik PH, Einzig AI. Taxol in malignant melanoma. J Natl Cancer Inst Monogr 1993:185-187.

[71] Gogas H, Bafaloukos D, Bedikian AY. The role of taxanes in the treatment of metastatic melanoma. Melanoma Res 2004;14:415-420.

[72] Zimpfer-Rechner C, Hofmann U, Figl R, Becker JC, Trefzer U, Keller I, et al. Randomized phase II study of weekly paclitaxel versus paclitaxel and carboplatin as secondline therapy in disseminated melanoma: a multicentre trial of the Dermatologic Cooperative Oncology Group (DeCOG). Melanoma Res 2003;13:531-536.

[73] Wiernik PH, Schwartz EL, Einzig A, Strauman JJ, Lipton RB, Dutcher JP. Phase I trial of taxol given as a 24-hour infusion every 21 days: responses observed in metastatic melanoma. J Clin Oncol 1987;5:1232-1239.

[74] Legha SS, Ring S, Papadopoulos N, Raber M, Benjamin RS. A PHASE-II TRIAL OF TAXOL IN METASTATIC MELANOMA. Cancer 1990;65.

[75] Einzig AI, Hochster H, Wiernik PH, Trump DL, Dutcher JP, Garowski E, et al. A phase II study of taxol in patients with malignant melanoma. Invest New Drugs 1991;9:59-64.

[76] Walker L, Schalch H, King DM, Dietrich L, Eastman M, Kwak M, et al. Phase II trial of weekly paclitaxel in patients with advanced melanoma. Melanoma Res 2005; 15:453-459.

[77] Bedikian AY, Plager C, Papadopoulos N, Eton O, Ellerhorst J, Smith T. Phase II evaluation of paclitaxel by short intravenous infusion in metastatic melanoma. Melanoma Research 2004;14. 
[78] Aamdal S, Wolff I, Kaplan S, Paridaens R, Kerger J, Schachter J, et al. Docetaxel (taxotere) in advanced malignant-melanoma - a phase-ii study of the eortc early clinicaltrials group. European Journal of Cancer 1994;30A.

[79] Rusthoven JJ. The evidence for tamoxifen and chemotherapy as treatment for metastatic melanoma. European Journal of Cancer 1998;34.

[80] Lens MB, Reiman T, Husain AF. Use of tamoxifen in the treatment of malignant melanoma. Cancer 2003;98:1355-1361.

[81] Karakousis CP, Lopez RE, Bhakoo HS, Rosen F, Moore R, Carlson M. Estrogen and progesterone receptors and tamoxifen in malignant melanoma. Cancer Treat Rep 1980;64:819-827.

[82] Creagan ET, Ahmann DL, Schutt AJ, Green SJ. Phase II study of mitolactol and semustine combination chemotherapy for advanced malignant melanoma. Cancer Treat Rep 1982;66:1425-1426.

[83] McCarty KS, Wortman J, Stowers S, Lubahn DB, Seigler HF. Sex steroid receptor analysis in human melanoma. Cancer 1980;46:1463-1470.

[84] Rosenberg SA, Dudley ME. Cancer regression in patients with metastatic melanoma after the transfer of autologous antitumor lymphocytes. Proc Natl Acad Sci U S A 2004;101 Suppl 2:14639-14645.

[85] Traynor K. Ipilimumab approved for metastatic melanoma. Am J Health Syst Pharm 2011;68:768.

[86] Verschraegen C. The monoclonal antibody to cytotoxic T lymphocyte antigen 4, ipilimumab, in the treatment of melanoma. Cancer Manag Res 2012;4:1-8.

[87] Ridolfi R, Chiarion-Sileni V, Guida M, Romanini A, Labianca R, Freschi A, et al. Cisplatin, dacarbazine with or without subcutaneous interleukin-2, and interferon alpha- $2 b$ in advanced melanoma outpatients: results from an Italian multicenter phase III randomized clinical trial. J Clin Oncol 2002;20:1600-1607.

[88] Bajetta E, Del Vecchio M, Nova P, Fusi A, Daponte A, Sertoli MR, et al. Multicenter phase III randomized trial of polychemotherapy (CVD regimen) versus the same chemotherapy (CT) plus subcutaneous interleukin-2 and interferon-alpha2b in metastatic melanoma. Ann Oncol 2006; 17:571-577.

[89] Agarwala SS, Kirkwood JM. Temozolomide in combination with interferon alpha-2b in patients with metastatic melanoma: a phase I dose-escalation study. Cancer 2003;97:121-127.

[90] Legha SS, Ring S, Bedikian A, Plager C, Eton O, Buzaid AC, et al. Treatment of metastatic melanoma with combined chemotherapy containing cisplatin, vinblastine and dacarbazine (CVD) and biotherapy using interleukin-2 and interferon-alpha. Annals of Oncology 1996;7. 
[91] Cascinelli N, Belli F, MacKie RM, Santinami M, Bufalino R, Morabito A. Effect of long-term adjuvant therapy with interferon alpha-2a in patients with regional node metastases from cutaneous melanoma: a randomised trial. Lancet 2001;358:866-869.

[92] Cameron DA, Cornbleet MC, Mackie RM, Hunter JA, Gore M, Hancock B, et al. Adjuvant interferon alpha $2 \mathrm{~b}$ in high risk melanoma - the Scottish study. Br J Cancer 2001;84:1146-1149.

[93] Hancock BW, Wheatley K, Harris S, Ives N, Harrison G, Horsman JM, et al. Adjuvant interferon in high-risk melanoma: the AIM HIGH Study--United Kingdom Coordinating Committee on Cancer Research randomized study of adjuvant low-dose extended-duration interferon Alfa-2a in high-risk resected malignant melanoma. J Clin Oncol 2004;22:53-61.

[94] Wheatley K, Ives N, Hancock B, Gore M, Eggermont A, Suciu S. Does adjuvant interferon-alpha for high-risk melanoma provide a worthwhile benefit? A meta-analysis of the randomised trials. Cancer Treat Rev 2003;29:241-252.

[95] Håkansson A, Gustafsson B, Krysander L, Håkansson L. Effect of IFN-alpha on tumor-infiltrating mononuclear cells and regressive changes in metastatic malignant melanoma. J Interferon Cytokine Res 1998;18:33-39.

[96] Yurkovetsky ZR, Kirkwood JM, Edington HD, Marrangoni AM, Velikokhatnaya L, Winans MT, et al. Multiplex analysis of serum cytokines in melanoma patients treated with interferon-alpha2b. Clin Cancer Res 2007;13:2422-2428.

[97] Garbe C, Eigentler TK, Keilholz U, Hauschild A, Kirkwood JM. Systematic Review of Medical Treatment in Melanoma: Current Status and Future Prospects. Oncologist 2011;16.

[98] Atkins MB, Robertson MJ, Gordon M, Lotze MT, DeCoste M, DuBois JS, et al. Phase I evaluation of intravenous recombinant human interleukin 12 in patients with advanced malignancies. Clin Cancer Res 1997;3:409-417.

[99] Atkins MB, Lotze MT, Dutcher JP, Fisher RI, Weiss G, Margolin K, et al. High-dose recombinant interleukin 2 therapy for patients with metastatic melanoma: analysis of 270 patients treated between 1985 and 1993. J Clin Oncol 1999;17:2105-2116.

[100] Dillman RO, Wiemann MC, VanderMolen LA, Bury MJ, DePriest C, Church C. Hybrid high-dose bolus/continuous infusion interleukin-2 in patients with metastatic melanoma: a phase II trial of the Cancer Biotherapy Research Group (formerly the National Biotherapy Study Group). Cancer Biother Radiopharm 1997;12:249-255.

[101] Keilholz U, Punt CJ, Gore M, Kruit W, Patel P, Lienard D, et al. Dacarbazine, cisplatin, and interferon-alfa- $2 b$ with or without interleukin-2 in metastatic melanoma: a randomized phase III trial (18951) of the European Organisation for Research and Treatment of Cancer Melanoma Group. J Clin Oncol 2005;23:6747-6755. 
[102] Atkins MB. Cytokine-based therapy and biochemotherapy for advanced melanoma. Clinical Cancer Research 2006;12.

[103] Balmer CM. Clinical use of biologic response modifiers in cancer treatment: an overview. Part II. Colony-stimulating factors and interleukin-2. DICP 1991;25:490-498.

[104] Bruton JK, Koeller JM. Recombinant interleukin-2. Pharmacotherapy 1994;14.

[105] Petrella T, Quirt I, Verma S, Haynes AE, Charette M, Bak K, et al. Single-agent interleukin-2 in the treatment of metastatic melanoma. Curr Oncol 2007;14:21-26.

[106] Contardi E, Palmisano GL, Tazzari PL, Martelli AM, Falà F, Fabbi M, et al. CTLA-4 is constitutively expressed on tumor cells and can trigger apoptosis upon ligand interaction. Int J Cancer 2005;117:538-550.

[107] Shah KV, Chien AJ, Yee C, Moon RT. CTLA-4 Is a Direct Target of Wnt/beta-Catenin Signaling and Is Expressed in Human Melanoma Tumors. Journal of Investigative Dermatology 2008;128.

[108] Queirolo P, Laurent S, Boitano M, Carrega P, Saverino D, Alviano F, et al. Targeting ctla-4 directly on melanoma cells: A possible novel perspective in the immunotherapy of cutaneous melanoma. Proc Am Soc Clin Oncol, 2009.

[109] Leach DR, Krummel MF, Allison JP. Enhancement of antitumor immunity by CTLA-4 blockade. Science 1996;271.

[110] Hurwitz AA, Foster BA, Kwon ED, Truong T, Choi EM, Greenberg NM, et al. Combination immunotherapy of primary prostate cancer in a transgenic mouse model using CTLA-4 blockade. Cancer Research 2000;60.

[111] Hodi FS, O'Day SJ, McDermott DF, Weber RW, Sosman JA, Haanen JB, et al. Improved survival with ipilimumab in patients with metastatic melanoma. $\mathrm{N}$ Engl J Med 2010;363:711-723.

[112] Robert C, Thomas L, Bondarenko I, O'Day S, M D JW, Garbe C, et al. Ipilimumab plus dacarbazine for previously untreated metastatic melanoma. $\mathrm{N}$ Engl J Med 2011;364:2517-2526.

[113] Sapoznik S, Hammer O, Ortenberg R, Besser MJ, Ben-Moshe T, Schachter J, et al. Novel anti-melanoma immunotherapies: disarming tumor escape mechanisms. Clin Dev Immunol 2012;2012:818214.

[114] Patel V, Gandhi H, Upaganlawar A. Ipilimumab: Melanoma and beyond. J Pharm Bioallied Sci 2011;3:546.

[115] Mansh M. Ipilimumab and cancer immunotherapy: a new hope for advanced stage melanoma. Yale J Biol Med 2011;84:381-389.

[116] Tarhini AA, Iqbal F. CTLA-4 blockade: therapeutic potential in cancer treatments. Onco Targets Ther 2010;3:15-25. 
[117] Thumar JR, Kluger HM. Ipilimumab: a promising immunotherapy for melanoma. Oncology (Williston Park) 2010;24:1280-1288.

[118] Maker AV, Yang JC, Sherry RM, Topalian SL, Kammula US, Royal RE, et al. Intrapatient dose escalation of anti-CTLA-4 antibody in patients with metastatic melanoma. J Immunother 2006;29:455-463.

[119] Serrone L, Zeuli M, Sega FM, Cognetti F. Dacarbazine-based chemotherapy for metastatic melanoma: thirty-year experience overview. J Exp Clin Cancer Res 2000;19:21-34.

[120] Del Prete SA, Maurer LH, O'Donnell J, Forcier RJ, LeMarbre P. Combination chemotherapy with cisplatin, carmustine, dacarbazine, and tamoxifen in metastatic melanoma. Cancer Treat Rep 1984;68:1403-1405.

[121] Lattanzi SC, Tosteson T, Chertoff J, Maurer LH, O'Donnell J, LeMarbre PJ, et al. Dacarbazine, cisplatin and carmustine, with or without tamoxifen, for metastatic melanoma: 5-year follow-up. Melanoma Res 1995;5:365-369.

[122] Chapman PB, Einhorn LH, Meyers ML, Saxman S, Destro AN, Panageas KS, et al. Phase III multicenter randomized trial of the Dartmouth regimen versus dacarbazine in patients with metastatic melanoma. J Clin Oncol 1999;17:2745-2751.

[123] Chiarion Sileni V, Nortilli R, Aversa SM, Paccagnella A, Medici M, Corti L, et al. Phase II randomized study of dacarbazine, carmustine, cisplatin and tamoxifen versus dacarbazine alone in advanced melanoma patients. Melanoma Res 2001;11:189-196.

[124] Su PJ, Chen JS, Liaw CC, Chang HK, Wang HM, Yang TS, et al. Biochemotherapy with carmustine, cisplatin, dacarbazine, tamoxifen and low-dose interleukin-2 for patients with metastatic malignant melanoma. Chang Gung Med J 2011;34:478-486.

[125] Atzpodien J, Neuber K, Kamanabrou D, Fluck M, Bröcker EB, Neumann C, et al. Combination chemotherapy with or without s.c. IL-2 and IFN-alpha: results of a prospectively randomized trial of the Cooperative Advanced Malignant Melanoma Chemoimmunotherapy Group (ACIMM). Br J Cancer 2002;86:179-184.

[126] Creagan ET, Suman VJ, Dalton RJ, Pitot HC, Long HJ, Veeder MH, et al. Phase III clinical trial of the combination of cisplatin, dacarbazine, and carmustine with or without tamoxifen in patients with advanced malignant melanoma. J Clin Oncol 1999;17:1884-1890.

[127] E B, MG Z, F N, N Z. Tamoxifen does not improve response when added to chemotherapy in metastatic melanoma. Proc Am Soc Clin Oncol, 1993: 393.

[128] McClay EF, McClay ME, Jones JA, Winski PJ, Christen RD, Howell SB, et al. A phase I and pharmacokinetic study of high dose tamoxifen and weekly cisplatin in patients with metastatic melanoma. Cancer 1997;79:1037-1043. 
[129] Antoine EC, Rixe O, Vuillemin E, Benhammouda A, Borel C, Ghironzi GC, et al. A phase II study of tamoxifen combined with cisplatin-interleukin 2 and alpha-interferon in metastatic melanoma. Am J Clin Oncol 1995;18:421-424.

[130] Rixe O, Benhammouda A, Antoine E. Final results of a prospective multicentric study on 91 metastatic malignant melanoma patients treated by chemo-imunotherapy with cisplatin, interleukin-2 and interferon-a. Proc Am Soc Clin OncoI, 1994: 399.

[131] Fierro MT, Bertero M, Novelli M, Appino A, Doveil GC, Colonna S, et al. Therapy for metastatic melanoma: effective combination of dacarbazine, carmustine, cisplatin and tamoxifen. Melanoma Res 1993;3:127-131.

[132] Johnson DH, Presant C, Einhorn L, Bartolucci AA, Greco FA. Cisplatin, vinblastine, and bleomycin in the treatment of metastatic melanoma - a phase-ii study of the southeastern-cancer-study-group. Cancer Treatment Reports 1985;69.

[133] Bajetta E, Rovej R, Buzzoni R, Vaglini M, Bonadonna G. Treatment of advanced malignant melanoma with vinblastine, bleomycin, and cisplatin. Cancer Treat Rep 1982;66:1299-1302.

[134] Nathanson L, Kaufman SD, Carey RW. Vinblastine, infusion, bleomycin, and cis-dichlorodiammine-platinum chemotherapy in metastatic melanoma. Cancer 1981;48:1290-1294.

[135] Seigler HF, Lucas VS, Pickett NJ, Huang AT. DTIC, CCNU, bleomycin and vincristine (BOLD) in metastatic melanoma. Cancer 1980;46:2346-2348.

[136] Vuoristo MS, Hahka-Kemppinen M, Parvinen LM, Pyrhonen S, Seppa H, Korpela M, et al. Randomized trial of dacarbazine versus bleomycin, vincristine, lomustine and dacarbazine (BOLD) chemotherapy combined with natural or recombinant interferon-alpha in patients with advanced melanoma. Melanoma Research 2005;15.

[137] Pyrhönen S, Hahka-Kemppinen M, Muhonen T, Nikkanen V, Eskelin S, Summanen $\mathrm{P}$, et al. Chemoimmunotherapy with bleomycin, vincristine, lomustine, dacarbazine (BOLD), and human leukocyte interferon for metastatic uveal melanoma. Cancer 2002;95:2366-2372.

[138] Kivelä T, Suciu S, Hansson J, Kruit WH, Vuoristo MS, Kloke O, et al. Bleomycin, vincristine, lomustine and dacarbazine (BOLD) in combination with recombinant interferon alpha-2b for metastatic uveal melanoma. Eur J Cancer 2003;39:1115-1120.

[139] Young DW, Lever RS, English JS, MacKie RM. The use of BELD combination chemotherapy in advanced malignant melanoma. Cancer 1985;55:1879-1881.

[140] Stables GI, Doherty VR, MacKie RM. Nine years' experience of BELD combination chemotherapy (bleomycin, vindesine, CCNU and DTIC) for metastatic melanoma. Br J Dermatol 1992;127:505-508. 
[141] Legha SS, Ring S, Papadopoulos N, Plager C, Chawla S, Benjamin R. A prospective evaluation of a triple-drug regimen containing cisplatin, vinblastine, and dacarbazine (CVD) for metastatic melanoma. Cancer 1989;64:2024-2029.

[142] Eton O, Legha SS, Bedikian AY, Lee JJ, Buzaid AC, Hodges C, et al. Sequential biochemotherapy versus chemotherapy for metastatic melanoma: results from a phase III randomized trial. J Clin Oncol 2002;20:2045-2052.

[143] Kim KB, Eton O, East MJ, Hodges C, Papadopoulos NE, Grimm EA, et al. Pilot study of high-dose, concurrent biochemotherapy for advanced melanoma. Cancer 2004;101:596-603.

[144] Jungnelius U, Ringborg U, Aamdal S, Mattsson J, Stierner U, Ingvar C, et al. Dacarbazine-vindesine versus dacarbazine-vindesine-cisplatin in disseminated malignant melanoma. A randomised phase III trial. European Journal of Cancer 1998;34.

[145] Ringborg U, Jungnelius U, Hansson J, Strander H. Dacarbazine-vindesine-cisplatin in disseminated malignant melanoma. A phase I-II trial. Am J Clin Oncol 1990;13:214-217.

[146] Hodi FS, Soiffer RJ, Clark J, Finkelstein DM, Haluska FG. Phase II study of paclitaxel and carboplatin for malignant melanoma. Am J Clin Oncol 2002;25:283-286.

[147] Rao RD, Holtan SG, Ingle JN, Croghan GA, Kottschade LA, Creagan ET, et al. Combination of paclitaxel and carboplatin as second-line therapy for patients with metastatic melanoma. Cancer 2006;106:375-382.

[148] Kottschade LA, Suman VJ, Amatruda T, McWilliams RR, Mattar BI, Nikcevich DA, et al. A phase II trial of nab-paclitaxel (ABI-007) and carboplatin in patients with unresectable stage IV melanoma : a North Central Cancer Treatment Group Study, N057E(1). Cancer 2011;117:1704-1710.

[149] Pflugfelder A, Eigentler TK, Keim U, Weide B, Leiter U, Ikenberg K, et al. Effectiveness of carboplatin and paclitaxel as first- and second-line treatment in 61 patients with metastatic melanoma. PLoS One 2011;6:e16882.

[150] Flaherty KT, Schiller J, Schuchter LM, Liu G, Tuveson DA, Redlinger M, et al. A phase I trial of the oral, multikinase inhibitor sorafenib in combination with carboplatin and paclitaxel. Clin Cancer Res 2008;14:4836-4842.

[151] Hauschild A, Grob JJ, Demidov LV, Jouary T, Gutzmer R, Millward M, et al. Dabrafenib in BRAF-mutated metastatic melanoma: a multicentre, open-label, phase 3 randomised controlled trial. Lancet 2012;380:358-365.

[152] Kim KB, Sosman JA, Fruehauf JP, Linette GP, Markovic SN, McDermott DF, et al. BEAM: a randomized phase II study evaluating the activity of bevacizumab in combination with carboplatin plus paclitaxel in patients with previously untreated melanoma. J Clin Oncol 2012;30:34-41. 
[153] Schmittel A, Schmidt-Hieber M, Martus P, Bechrakis NE, Schuster R, Siehl JM, et al. A randomized phase II trial of gemcitabine plus treosulfan versus treosulfan alone in patients with metastatic uveal melanoma. Ann Oncol 2006;17:1826-1829.

[154] Schmittel A, Schuster R, Bechrakis NE, Siehl JM, Foerster MH, Thiel E, et al. A twocohort phase II clinical trial of gemcitabine plus treosulfan in patients with metastatic uveal melanoma. Melanoma Res 2005;15:447-451.

[155] Lopez M, Perno CF, Di Lauro L, Papaldo P, Ganzina F, Barduagni A. Controlled study of DTIC versus DTIC plus epirubicin in metastatic malignant melanoma. Invest New Drugs 1984;2:319-322.

[156] Minchom A, Young K, Larkin J. Ipilimumab: showing survival benefit in metastatic melanoma. Future Oncol 2011;7:1255-1264.

[157] Hersh EM, O'Day SJ, Powderly J, Khan KD, Pavlick AC, Cranmer LD, et al. A phase II multicenter study of ipilimumab with or without dacarbazine in chemotherapy-naive patients with advanced melanoma. Invest New Drugs 2011;29:489-498.

[158] Davies H, Bignell GR, Cox C, Stephens P, Edkins S, Clegg S, et al. Mutations of the BRAF gene in human cancer. Nature 2002;417:949-954.

[159] Falchook GS, Long GV, Kurzrock R, Kim KB, Arkenau TH, Brown MP, et al. Dabrafenib in patients with melanoma, untreated brain metastases, and other solid tumors: a phase 1 dose-escalation trial. Lancet 2012;379:1893-1901.

[160] Falchook GS, Lewis KD, Infante JR, Gordon MS, Vogelzang NJ, Demarini DJ, et al. Activity of the oral MEK inhibitor trametinib in patients with advanced melanoma: a phase 1 dose-escalation trial. Lancet Oncol 2012;13:782-789.

[161] Schmitt CA, Rosenthal CT, Lowe SW. Genetic analysis of chemoresistance in primary murine lymphomas. Nat Med 2000;6:1029-1035.

[162] Jansen B, Schlagbauer-Wadl H, Brown BD, Bryan RN, van Elsas A, Müller M, et al. bcl-2 antisense therapy chemosensitizes human melanoma in SCID mice. Nat Med 1998;4:232-234.

[163] Klasa RJ, Gillum AM, Klem RE, Frankel SR. Oblimersen Bcl-2 antisense: facilitating apoptosis in anticancer treatment. Antisense Nucleic Acid Drug Dev 2002;12:193-213.

[164] de Murcia G, Ménissier de Murcia J. Poly(ADP-ribose) polymerase: a molecular nicksensor. Trends Biochem Sci 1994;19:172-176.

[165] Plummer R, Jones C, Middleton M, Wilson R, Evans J, Olsen A, et al. Phase I study of the poly(ADP-ribose) polymerase inhibitor, AG014699, in combination with temozolomide in patients with advanced solid tumors. Clin Cancer Res 2008;14:7917-7923.

[166] Kashani-Sabet M, Shaikh L, Miller JR, Nosrati M, Ferreira CM, Debs RJ, et al. NFkappa B in the vascular progression of melanoma. J Clin Oncol 2004;22:617-623. 
[167] Ascierto PA, Streicher HZ, Sznol M. Melanoma: a model for testing new agents in combination therapies. J Transl Med 2010;8:38.

[168] Portnow J, Frankel P, Koehler S, Twardowski P, Shibata S, Martel C, et al. A phase I study of bortezomib and temozolomide in patients with advanced solid tumors. Cancer Chemother Pharmacol 2012;69:505-514.

[169] Neumann E, Schaefer-Ridder M, Wang Y, Hofschneider PH. Gene transfer into mouse lyoma cells by electroporation in high electric fields. EMBO J 1982;1:841-845.

[170] Hargrave B, Downey H, Strange R, Murray L, Cinnamond C, Lundberg C, et al. Electroporation-mediated gene transfer directly to the swine heart. Gene Ther 2012.

[171] Mir LM. Therapeutic perspectives of in vivo cell electropermeabilization. Bioelectrochemistry 2001;53:1-10.

[172] Marty M, Sersa G, Garbay JR, Gehl J, Collins CG, Snoj M, et al. Electrochemotherapy - An easy, highly effective and safe treatment of cutaneous and subcutaneous metastases: Results of ESOPE study. Ejc Supplements 2006;4.

[173] Sersa G, Stabuc B, Cemazar M, Miklavcic D, Rudolf Z. Electrochemotherapy with cisplatin: the systemic antitumor effectiveness of cisplatin can be potentiated locally by the application of electric pulses in the treatment of malignant melanoma skin metastases. Melanoma Res 2000;10:381-385.

[174] Kis E, Oláh J, Ócsai H, Baltas E, Gyulai R, Kemény L, et al. Electrochemotherapy of cutaneous metastases of melanoma--a case series study and systematic review of the evidence. Dermatol Surg 2011;37:816-824.

[175] Campana LG, Valpione S, Mocellin S, Sundararajan R, Granziera E, Sartore L, et al. Electrochemotherapy for disseminated superficial metastases from malignant melanoma. Br J Surg 2012;99:821-830.

[176] Venturini M, Pilla L, Agostini G, Cappio S, Losio C, Orsi M, et al. Transarterial Chemoembolization with Drug-eluting Beads Preloaded with Irinotecan as a First-Line Approach in Uveal Melanoma Liver Metastases: Tumor Response and Predictive Value of Diffusion-weighted MR Imaging in Five Patients. Journal of Vascular and Interventional Radiology 2012;23.

[177] Huppert PE, Fierlbeck G, Pereira P, Schanz S, Duda SH, Wietholtz H, et al. Transarterial chemoembolization of liver metastases in patients with uveal melanoma. Eur J Radiol 2010;74:38-44.

[178] Schuster R, Lindner M, Wacker F, Krössin M, Bechrakis N, Foerster MH, et al. Transarterial chemoembolization of liver metastases from uveal melanoma after failure of systemic therapy: toxicity and outcome. Melanoma Res 2010;20:191-196.

[179] Rosenberg SA, Restifo NP, Yang JC, Morgan RA, Dudley ME. Adoptive cell transfer: a clinical path to effective cancer immunotherapy. Nat Rev Cancer 2008;8:299-308. 
[180] Dudley ME, Wunderlich JR, Shelton TE, Even J, Rosenberg SA. Generation of tumorinfiltrating lymphocyte cultures for use in adoptive transfer therapy for melanoma patients. J Immunother 2003;26:332-342.

[181] Dudley ME, Wunderlich JR, Yang JC, Sherry RM, Topalian SL, Restifo NP, et al. Adoptive cell transfer therapy following non-myeloablative but lymphodepleting chemotherapy for the treatment of patients with refractory metastatic melanoma. J Clin Oncol 2005;23:2346-2357.

[182] Dudley ME, Yang JC, Sherry R, Hughes MS, Royal R, Kammula U, et al. Adoptive cell therapy for patients with metastatic melanoma: evaluation of intensive myeloablative chemoradiation preparative regimens. J Clin Oncol 2008;26:5233-5239.

[183] Rosenberg SA, Yang JC, Sherry RM, Kammula US, Hughes MS, Phan GQ, et al. Durable complete responses in heavily pretreated patients with metastatic melanoma using T-cell transfer immunotherapy. Clin Cancer Res 2011;17:4550-4557.

[184] Joseph RW, Peddareddigari VR, Liu P, Miller PW, Overwijk WW, Bekele NB, et al. Impact of clinical and pathologic features on tumor-infiltrating lymphocyte expansion from surgically excised melanoma metastases for adoptive T-cell therapy. Clin Cancer Res 2011;17:4882-4891.

[185] Tran KQ, Zhou J, Durflinger KH, Langhan MM, Shelton TE, Wunderlich JR, et al. Minimally cultured tumor-infiltrating lymphocytes display optimal characteristics for adoptive cell therapy. J Immunother 2008;31:742-751.

[186] Syed DN, Mukhtar H. Botanicals for the prevention and treatment of cutaneous melanoma. Pigment Cell Melanoma Res 2011;24:688-702.

[187] Locatelli C, Rosso R, Santos-Silva MC, de Souza CA, Licinio MA, Leal P, et al. Ester derivatives of gallic acid with potential toxicity toward L1210 leukemia cells. Bioorganic \& Medicinal Chemistry 2008;16:3791-3799.

[188] Locatelli C, Leal PC, Yunes RA, Nunes RJ, Creczynski-Pasa TB. Gallic acid ester derivatives induce apoptosis and cell adhesion inhibition in melanoma cells: The relationship between free radical generation, glutathione depletion and cell death. Chem Biol Interact 2009;181:175-184.

[189] de Cordova CAS, Locatelli C, Assuncao LS, Mattei B, Mascarello A, Winter E, et al. Octyl and dodecyl gallates induce oxidative stress and apoptosis in a melanoma cell line. Toxicology in Vitro 2011;25:2025-2034.

[190] Locatelli C, Carvalho DR, Mascarello A, de Cordova CA, Yunes RA, Nunes RJ, et al. Antimetastatic activity and low systemic toxicity of tetradecyl gallate in a preclinical melanoma mouse model. Invest New Drugs 2011. 